\title{
Numerical modeling of the piston effect in longitudinal ventilation systems for subway tunnels
}

\author{
Marta López González ${ }^{1}$, Mónica Galdo Vega ${ }^{2}$, \\ Jesús Manuel Fernández Oro ${ }^{2}$, Eduardo Blanco Marigorta ${ }^{2}$ \\ ${ }^{1}$ Airbus Operations GmbH, Finkenwerder (Hamburg) - Germany. \\ ${ }^{2}$ Area de Mecánica de Fluidos, Universidad de Oviedo, Campus de Viesques 33271, \\ Gijón (Asturias) - Spain. \\ Corresponding author: galdomonica@uniovi.es
}

\begin{abstract}
This paper analyzes the influence of the piston effect in the longitudinal ventilation system of subway tunnels using numerical methodologies. This aerodynamic effect, highly complex, three-dimensional and unsteady is modeled using Computational Fluid Dynamics (CFD) in order to simulate and analyze in detail the flow patterns associated to this effect. This approach improves the description provided by typical conventional tools, based on 1-D numerical modeling, and constitutes a useful benchmark for calibrating existing tunnel environment simulation software. For this study, a 3D computational model for a typical subway line between two consecutive stations has been considered. The implemented geometry is a typical configuration that mimics any modern infrastructure with $100 \mathrm{~m}$ long stations connected through a two-way tunnel, $500 \mathrm{~m}$ in length. The ventilation system is longitudinal, composed of two inlet shafts, with mechanical ventilation for each station, and an exhaust shaft in the middle of the tunnel. Additionally, at the tunnel edges, close to the stations, there are also natural ventilation shafts or draught relief shafts (DRS) - i.e. without mechanical fans - to attenuate possible pressure fluctuations originating from the piston effect.

The numerical simulation has been conducted using the commercial code, FLUENT, developing an unsteady numerical model with a dynamic mesh technique to simulate the train displacement between the two stations. Different cases have been studied in detail, including a wide range of ventilation conditions, as well as travel frequencies (single train and two trains crossing halfway). The main objective of this analysis has been the definition and quantification of the different parameters influencing the subway ventilation system. Finally, the impact of the piston effect on the global ventilation performance has also been addressed via numerical estimation.
\end{abstract}

\section{Introduction}

Nowadays, public transport systems have become an essential service in our modern daily lives. Among all the means of transport available in today's large cities, the subway is the most advantageous in terms of massive capacity, frequency and reliability. However, despite being the most efficient and sustainable option, it regular operation requires large amounts of energy. In particular, underground transportation 
systems have significant impacts on energy consumption at a regional scale (e.g., London Underground is the largest consumer of electricity in London and rates amongst the top 10 electricity consumers in the UK - London Underground Environment Report, 2006). In contrast to other travel systems, a very important fraction of the total consumption is not directly related to transport, but assigned to secondary subsystems as lighting or ventilation. Large metropolitan areas, like Seoul or Barcelona, may have rail networks with total lengths in the order of $100-150 \mathrm{~km}$, and total annual consumption of energy in the range of 200 million kWh per year (TMB, 2010). Approximately, $30-40 \%$ of that network energy is employed for non-traction electricity consumption (Hu et al., 2006; SEAM4US Project, 2011), where ventilation systems represent the largest portion. Table 1 summarizes typical distributions of auxiliary systems in terms of percentage and total amount of energy per passenger and year (adapted from Hong et al., 2004).

Table 1. Operating Metro Subsystems (non-traction energy consumptions) ${ }^{[1]}$ Total annual energy per passenger and per network area.

\begin{tabular}{lccc}
\hline \multicolumn{1}{c}{ Facilities in Subway Stations } & Ratio & $\mathrm{kJ} / \mathrm{pass}$. & $\mathrm{MJ} / \mathrm{m}^{2}$ \\
\hline Mechanical ventilation & $55.0 \%$ & 107 & 157 \\
HVAC systems in Stations & $18.5 \%$ & 35 & 53 \\
Lighting (transformer \& electricity rooms) & $9.0 \%$ & 17 & 25 \\
Elevators, escalators & $17.5 \%$ & 33 & 50 \\
\hline
\end{tabular}

${ }^{[1]}$ Data from Seoul Subway Lines \& Stations, with an estimation of the overall energy consumption of the Metro Stations around 70 million $\mathrm{kWh} / \mathrm{year}$ and 3.75 million users per day.

In modern underground facilities, the energy consumption related to ventilation and HVAC systems represents about $75 \%$ of the total energy for non-traction purposes. Consequently, the expense for cities like Barcelona or Seoul can be as high as 50 million kWh, up to 200 million for London (network length of $400 \mathrm{~km}$ ) and even 500 million for the New York Metropolitan Area (more than 1000 km in length). Obviously, an optimal management of the ventilation system would imply a large energy saving in absolute terms. In addition to these energetic requirements, ventilation systems are essential to guarantee optimal levels of comfort and safety for the passengers.

Unfortunately, underground tunnel ventilation is complex and inherently related to the dynamic effects generated by the rolling stock on the flow behavior. This means that, usually, a deep and customized analysis has to be performed for the definition of practical guidelines to optimize the overall performance.

There are a wide number of flow effects to be considered during the operation of ventilation systems: pressure variations (from low pressures due to the suction regions to high pressures in stagnation zones), flow currents due to normal ventilation operation, primary and secondary flows due to the three-dimensionality of the domains, induced flow currents due to changes in boundary conditions (open doors, train displacements, thermal imbalances,...) and even sonic shock in case of high-speed trains (Bopp et al., 2009). The most important induced flow currents are those provoked by the rapid displacement of the trains in the tunnels, establishing the socalled "piston effect", which is responsible for a significant air recirculation within 
subway tunnels and connecting stations (Lin et al., 2008). Hence, when a train enters into a tunnel, it induces a notable acceleration of the air in the tunnel, previously at rest. The air is then accelerated to velocities ranging from 3 to $8 \mathrm{~m} / \mathrm{s}$, except in the gap between the train and the tunnel where the air flow velocity can be a $30 \%$ higher than the train velocity due to the section decrease associated to the train blockage (Bopp et al., 2009). This effect, unavoidably associated to the running trains, induces an additional flow rate that enhances the tunnel ventilation and may be considered as a supplementary mechanism to relief the mechanical ventilation. Consequently, this fact justifies the analysis, either numerical or experimental, of the piston effect as a beneficial contributor in the ventilation systems, and evidences its potential to be included in current protocols for the operation and optimization of such systems.

The piston effect is basically the consequence of a stagnation pressure in the front area and the low pressure in the rear, as the train moves along the tunnel (see sketch in Figure 1). The higher pressure at the front pushes the air ahead, while the low pressure developed at the rear establishes a suction flow when the train has passed away. As a consequence, a ventilation shaft in the central part of the tunnel experiences an outflow when the train advances towards the shaft (positions $A, B$ in the Figure 1) and an inflow once the train passes by (locations $C$ and $D$ in the sketch). $A$ similar response is found in the pressure at the central point of the tunnel, with a sudden increase of the pressure when the train nose reaches the central shaft, followed by an abrupt pressure decay induced by the train wake.

\section{Figure 1. Instantaneous flow rate and static pressure in the central shaft of a typical longitudinal ventilation system due to the piston effect (adapted from Krasyuk et al., 2007, and Kim et al., 2009).}

The time-resolved evolution of the instantaneous flow rate in the draught relief shaft (DRS) is a perfect indicator of the impact of the piston effect on the ventilation system. Recently, both experimental and numerical approaches have been considered in the literature to observe the overall trends associated with the piston effect in different underground configurations. Experimentally, Lin et al., 2007, have addressed the influence of DRS performance with intensive measurements of the unsteady velocity and temperature in a real station. Complementarily, Krasyuk et al., 2007, have also characterized a real station of the Novosibirsk Metro and proposed an hydraulic correction that considers the influence of the piston effect as a moving pressure loss for low-speed trains in subway environments. Other works, like those by Kim et al., 2006, have employed scaled models to reproduce the train aerodynamics in a controlled environment in the laboratory and computational simulations to study the flow through compensating shafts. Numerically, CFD methodologies have begun to be considered for the optimization and design of operating practices in the daily management of subway stations. For instance, Huang et al., 2010, have employed a layering algorithm to analyze the train-induced unsteady airflow for natural ventilation; while Ke et al., 2002, used computational tools to optimize the design of control systems in a subway environment. Other authors, like Yang et al., 2008, have introduced the analysis of temperature distributions in underground platforms with an 
immersed mesh technique, and even provided validation with flow patterns and temperature distributions measured experimentally (El-Bialy et al., 2010).

In this paper, different cases of ventilation have been evaluated, including the superimposed effect of the airflow induced by the train movement, allowing the estimation of the total amount of air displaced by the piston effect during a typical operating cycle of a scheduled train. In particular, several cases have been defined to study the influence of different parameters on the performance of the piston effect over longitudinal ventilation systems. The underlying objective has been the exploration of dynamic mesh techniques for CFD computations in order to address the piston effect via numerical simulation and to estimate a global performance in aerodynamic terms for optimal operation of underground stations.

\section{Numerical methodology}

The influence of the piston effect over the longitudinal ventilation system in a typical subway tunnel has been addressed numerically with a CFD unsteady, 3D model composed by two adjacent stations linked by a tunnel segment. The tunnel has been implemented with a double track so train displacements could be simulated in both directions, even considering halfway crossing trains. Basic dimensions for the different transversal sections, the tunnel length and the overall size of the stations platforms and entrances have been chosen according to typical values found in current underground networks (SEAM4US Project, 2011). Over this geometry, the differential equations for mass conservation, momentum and turbulent closure have been resolved iteratively over a cell-centered formulation of the Finite Volume Method.

Geometry and baseline dimensions. Characteristic dimensions for the train and the tunnel section have been adopted from typical railway stations. In particular, a planar $3 \times 3.5 \mathrm{~m}^{2}$ area was defined for the train front and a horseshoe section of 35.6 $\mathrm{m}^{2}$ for the tunnel connecting both stations. The ratio between both areas, denominated as blockage factor $(\delta)$, has a typical value of 0.3 (0.6 in case of two crossing trains in opposite directions). Additionally, the stations are defined with 100 $\mathrm{m}$ length, $6 \mathrm{~m}$ height and $26 \mathrm{~m}$ width, with lateral platforms of $5 \mathrm{~m}$ wide for the passengers. This implies an approximate total volume of $19,500 \mathrm{~m}^{3}$, including the users access areas with $5 \times 5$ and $5 \times 10 \mathrm{~m}^{2}$ layouts. The tunnel connecting the stations is $500 \mathrm{~m}$ in length and the subway trains are $65 \mathrm{~m}$ long.

For the ventilation shafts, rectangular sections of $2 \times 2 \mathrm{~m}^{2}$ have been implemented in the model according to recommended practical guidelines in the literature (Gawthorpe, 2010). The average depth of the line is fixed to $20 \mathrm{~m}$ so the geometry has been extruded up to that height to simulate the users entrances and the exhaust tubes of the compensation shafts. Mechanical ventilation has been also considered in the study with injection and extraction areas of $2 \times 4 \mathrm{~m}^{2}$ where the flow is forced to blow inside/outside the tunnel. Finally, additional tunnel segments at the opposite ends of both stations have been introduced to isolate the flow behavior of the piston effect in the tunnel from other fluid dynamic perturbations (reflections, non-realistic pressure and/or velocity distributions, etc...). Figure 2 shows a sketch with all the 
aforementioned relevant elements and the designation adopted for this tunnel configuration.

Figure 2. Sketch of the numerical domain for a longitudinal ventilation system with central mechanical ventilation.

Mesh characteristics. A structured mesh has been used for the whole geometry, with a typical number of cells in the cross section taken from the reference values found in the literature (Colella et al., 2010, Galdo et al., 2008). For the longitudinal direction, a grid sensitivity analysis has been conducted to characterize the effect of the mesh density over the solution of the piston effect flow patterns. Figure 3 shows the five different meshes employed in the study, ranging from 2,500 to 50,000 cells in the longitudinal direction. The results obtained from the case with 50,000 cells are assumed to be sufficiently grid-independent for this type of application.

Figure 3. Grid independence analysis for the streamwise spatial discretization. Details of the 2D mesh (longitudinal section) over the train domain.

The temporal evolution of the mass flow rate induced by the train movement in the ventilation shaft number 3 , and the unsteady value of the streamwise velocity at a characteristic central point inside the tunnel have been monitored to analyze the influence of the mesh density. It is clearly observed that coarse meshes present large discrepancies, especially for the outflow at the ventilation shaft, due to a higher numerical diffusion. A grid density around 20,000 cells has been found to give excellent results in terms of computational cost and numerical precision, with deviations lower than $0.5 \%$. The final selection includes additional refinement at the train front.

Figure 4 shows the mesh characteristics in the cross section, with 3,000 nodes approximately. An adaptive pattern has been employed, clustering more cells towards the relevant solid boundaries, i.e. train sidewalls and tunnel and stations walls. Other regions, where flow gradients are expected to be significantly lower, have been meshed with coarse grids in order to economize the total number of cells. Thus, the transversal mesh presents a total number of 820 cells $/ \mathrm{m}$ in the tunnel section, 700 cells $/ \mathrm{m}$ in the station section (with 600 to 700 cells $/ \mathrm{m}$ for the entrance areas to the platforms) and 144 cells $/ \mathrm{m}$ in the ventilation shafts.

Figure 4. 2D Mesh distributions in the transversal section of the stations.

With respect to the final 3D mesh adopted for the study, bell-shaped and successive ratio distributions have also been employed along the longitudinal 
coordinate to achieve a progressive, smooth grid density with a rational arrangement of the cells, clustering them at the most pertinent locations: areas contractions, ventilations shafts and flow inlets and outlets. With these optimization strategies, the total number of cells reached up to 1.3 million, in accordance with current requirements for CFD simulations of airflows in underground stations (SEAM4US Project, 2011). Figure 5 shows a 3D view of the mesh in one of the stations.

Figure 5. Three-dimensional mesh used in the metro stations.

Boundary conditions. Concerning operative parameters and boundary conditions, in addition to the four relief shafts (DRS) and the users entrances, an injection shaft in each station and an extraction shaft in the middle of the tunnel are employed for the ventilation system (Figure 6).

Every injection shaft is defined with an inlet volumetric flow rate of $120,000 \mathrm{~m}^{3} / \mathrm{h}$ of fresh air, a typical value for this type of installations (SEAM4US Project, 2011). Besides, different outflow conditions were imposed in the aspirating shafts for this study. First of all, a case without mechanical extraction, i.e. a closed mid-tunnel vent shaft, is considered. Following, four different mechanical extractions, ranging from 150,000 to $360,000 \mathrm{~m}^{3} / \mathrm{h}$ and designated as "Infra, Under, Neutral and OverVentilation databases", were studied (see Table 2). This classification corresponds to the net balance between inflow and outflow rates (i.e., the neutral condition presents a $240,000 \mathrm{~m}^{3} / \mathrm{h}$ outflow in the mid-tunnel shaft and a $120,000 \mathrm{~m}^{3} / \mathrm{h}$ inflow in each of the two stations connected by the tunnel, that is, $2 \times 120,000 \mathrm{~m}^{3} / \mathrm{h}$ total inflow).

In natural ventilation cases, the flow patterns inside the tunnel are exclusively a consequence of temperature and pressure differences with respect to outside surface conditions. Because external thermal conditions have an important influence in the chimney effect found in vertical shafts, it is clear that natural ventilation is affected by environmental and seasonal variations, so long-term simulations would be required (several months executions) to model this effect accurately. Obviously, this is impractical so here only a baseline performance is considered, with no thermal differences between interior and exterior conditions. The rest of the cases -with mechanical ventilation- are also solved with an isothermal approach, assuming that thermodynamics play a marginal role for this type of confined airflows induced by train-motion (Yan et al., 2013).

For the compensation shafts and the users entrances, a static pressure condition was established at the outlet sections, with a value equal to the atmospheric pressure. 
Table 2. Operating scenarios for the longitudinal ventilation system.

\begin{tabular}{lccc}
\hline $\begin{array}{c}\text { Numerical database (steady, single-train and } \\
\text { double-train unsteady dynamic mesh) }\end{array}$ & $\begin{array}{c}\text { Total } \\
\text { inflow }^{[1]} \\
\left(\mathrm{m}^{3} / \mathrm{h}\right)\end{array}$ & $\begin{array}{c}\text { Total } \\
\text { outflow } \\
\left(\mathrm{m}^{3} / \mathrm{h}\right)\end{array}$ & $\begin{array}{c}\text { Outflow/ } \\
\text { inflow } \\
\text { Ratio }\end{array}$ \\
\hline Case 0. Natural ventilation & - & - & - \\
Case 1. Without mechanical extraction & 240,000 & 0 & 0 \\
Case 2. Infra-ventilation & 240,000 & 150,000 & 0.625 \\
Case 3. Under-ventilation & 240,000 & 180,000 & 0.75 \\
Case 4. Neutral ventilation & 240,000 & 240,000 & 1.00 \\
Case 5. Over-ventilation & 240,000 & 360,000 & 1.50 \\
\hline
\end{tabular}

${ }^{[1]} 120,000 \mathrm{~m}^{3} / \mathrm{h}$ inflow in each of the stations connected by the tunnel.

Figure 6. Definition of boundary conditions and dynamic mesh domains. P-O: Pressure Outlets (atmospheric); V-I: Velocity-Inlets.

Solver and numerical schemes. The commercial code, FLUENT v6.3, based on a finite volume formulation has been employed for the computations. Additionally, the $k-\varepsilon$ turbulence model has been used due to its well-known accuracy for this type of internal flow applications (Ballesteros et al., 2006). On this study, a second order, upwind discretization was used for convective terms and a central difference scheme was used for diffusive terms.

Dynamic mesh procedure. The train displacement has been implemented using a dynamic mesh with a layering algorithm, because its superior ability to work with structured mesh under linear movement. In essence, this technique creates and collapses complete rows of cells when the train front area advances a prescribed threshold. To work properly, it is necessary to divide the whole domain in several parts, so cells can be created or destroyed depending on its relative position respect to the train nose (Figure 6). In particular, two extreme surfaces define the location where cells emerge or collapse, whereas two fluid zones between these surfaces and the train are actually implemented as moving zones using a user defined function (UDF). This functionality of the code allows the implementation of a velocity profile for the trains which it is automatically updated within the course of the unsteady simulation. Following guidelines from previous studies (Kim et al., 2009), the velocity pattern imposed is divided in three different stages. First, the train is progressively accelerated from rest in the first station until it reaches a constant cruise velocity of $60 \mathrm{~km} / \mathrm{h}$. This velocity is maintained during $30 \mathrm{~s}$. Finally, the train goes through the third stage where it is decelerated, stopping at the second station. The whole cycle lasts around $42 \mathrm{~s}$ to complete the $500 \mathrm{~m}$ long distance between the stations.

Unsteady simulation and numerical stability. The unsteady modeling was resolved using a characteristic time step of $0.05 \mathrm{~s}$, which was found to be particularly suitable to describe the dynamic behavior of primary flow patterns with sufficient precision. Since the total simulation time is $42 \mathrm{~s}$ for the running train, a total number of 4200 time steps, with approximately 50 iterations for each time step, were necessary 
to resolve each case. Thus, more than $200 \mathrm{~h}$ of CPU time in a 4-node PC cluster were required to complete the numerical database.

\section{Figure 7. Evolution of the mass flow rate through DRS\#3 as a function of the ventilation conditions (results for one train going from Station 1 to Station 2).}

\section{Results and discussion}

Unsteady flow rates established by the piston effect. This section analyzes in detail the most relevant conclusions extracted from the results of the simulation. As a starting point, the impact of the piston effect inside the tunnel conditions is firstly reviewed. For that purpose, Figure 7 shows the instantaneous flow rate at the compensation shaft 3, which is placed 5 meters inside the tunnel from Station 2 . In the $x$-axis, the distance travelled by the train from Station 1 , as well as the temporal coordinate, are employed to track the evolution over time. Here, positive values represent an inflow through the shaft into the system. An additional sketch shows the train positions involving relevant changes in the flow rate conditions.

Before going into the detailed discussion of this figure, an analytical 1-D model has been developed to contrast the 3-D results provided by the CFD code, and the comparison will be shown in Figure 8. Similar analysis can be done using available 1-D commercial software like SES, Thermotun or IDA Tunnel. Classical expressions for friction and minor losses have been considered with typical loss coefficients for contractions, expansions and bifurcations found in the literature. The piston effect of the train has been introduced as a pressure difference that takes into account the blockage factor between the tunnel and train sections and the overall drag over the train (function of the train drag coefficient, $C_{D}$ ), or a "resistance factor" (following the convention used in the paper by Krasyuk et al, 2007). A similar analogy, considering the train as a pump that provides a pressure jump in the tunnel, has been confirmed to provide identical results.

In particular, the case without mechanical extraction has been used for comparison due to the lower inertial effects for the flow rate established in the tunnel. With these ventilation conditions, two different train positions have been analyzed. First, when the train is running close to the mid-tunnel mechanical extraction ("baseline" case), and second, when the train has passed the DRS\#3 and the maximum inflow rate is established in that compensation shaft ("peak" value). Additionally, two different values of $C_{D}$ have been tested to calibrate the "strength" of the piston effect. A theoretical value, given by a 1-D control volume analysis of a rectangular obstacle (train) in the relative frame, which is exclusively a function of the blockage factor $\left(\delta=0.3\right.$ in our case) according to $C_{D}=\delta /(1-\delta)^{2} \approx 0.6$; and a corrected value for trains in tunnels (European Normative, EN 14067-3:2003) that in this case results in a $C_{D}=2 \delta /(1-$ $2 \delta) \approx 1.5$ (this value is also in consonance with the one used in the paper by Krasyuk et al., 2007).

The schematic diagrams at the bottom of Figure 8 show the one-dimensional balance of flow rates established in the line for a "weak", theoretical piston effect $\left(C_{D}\right.$ 
$\approx 0.6$ ). Both peak and baseline simulations are represented in these colored diagrams. In the case of the baseline condition, an outlet flow rate about $22,600 \mathrm{~m}^{3} / \mathrm{h}$ is predicted by the simplified modeling, while an inlet flow rate of $31,700 \mathrm{~m}^{3} / \mathrm{h}$ is obtained for the peak situation. At the top of the figure, the flow rates predicted by the 1-D model through DRS\#3 are directly compared with the CFD results previously given in Figure 7 for both theoretical and corrected drag coefficients. A maximum deviation (overestimation) of an $18 \%$ is obtained for the peak value of the corrected case respect to the 3D computations. Similar percentages of difference between 1-D and 3-D are found in the other cases analyzed. This means that both numerical methodologies are coherent in the definition of the basic flow features, providing the same overall trends for the balance of inlet/outlet flows in the tunnel. However, at the same time, they show important differences in the instantaneous flow rate induced by the train motion, which may be very relevant if a precise measurement of the ventilation savings provided by the piston effect is to be given. In that respect, 3D computations may be the right option for optimal precision in the calculations and show the possibilities for calibration of conventional 1-D software.

\section{Figure 8. Comparison of results provided by both 1-D and 3-D approaches for the scenario without mechanical extraction.}

Next, a deep analysis of the flow evolution for the different scenarios is done from the results shown in Figure 7. The figure shows that the evolution of the flow rate presents analogous profiles whatever ventilation system is simulated. However, maximum and mean values are influenced by the conditions of the scenario.

In the first zone, the train is progressively accelerated, its velocity is low and the distance to the DRS\#3 is still quite large (before position A). The flow rates in this zone are mainly constant because the train is still out of the tunnel. For the natural ventilation, flow rates are initially negligible, whereas for mechanical ventilation conditions, they range from negative (case only with impulsion, without mechanical extraction) to positive values (cases combining impulsion in the stations with an extraction in the mid-tunnel). After the train reaches section $A$, the slope of the evolution turns to be negative and the flow rate is progressively diminished, as a consequence of the train entering into the tunnel. This provokes a pressure wave that induces an air current in phase with the train displacement. The slope is reduced at section $B$, exactly where the compensation shaft 2 is located. Also notice the changes in the behavior between the different ventilation conditions. For both natural and nonmechanical extraction ventilations, the slope is notably decreased, and it even disappears, so the outflow through DRS\#3 remains practically constant. On the contrary, for those cases with a certain extraction, there is an appreciable, but moderate slope. This variation comes, firstly, from the suction effect that the rear part of the train provokes on the shaft after passing by; and secondly, because of the progressive increase of the piston effect overpressure as the train reaches the relief shaft.

Cases with mechanical extraction in the tunnel mid-position (section C) experience an additional change in the slope of the shaft flow rate (precisely when the train passes by that section). To illustrate this characteristic, Figure 9 has been introduced to 
show the pressure map inside the tunnel for the over-ventilation case. Before the train passes the central shaft (map on top), all the tunnel presents negative pressures so there is a net inflow through DRS\#3 (see the right detail with incoming velocity vectors). On the contrary, once the train passes the central section (bottom map), the flow induced by the front of the train goes towards Station 2, instead of being extracted through the central exhaust, and thus a net outflow through the compensation shaft is established (see now the outgoing velocity vectors). These effects are obviously absent for both natural and w/o mechanical outflow ventilation because of the lack of central extraction shaft.

Figure 9. Contour maps of static pressure inside the tunnel as the train passes through the central shaft, for the over-ventilated scenario. Detail of the flow in DRS\#3

The most important zones are those located between sections $D$ and $F$, where the influence of the piston effect on the inlet flow on DRS\#3 is clearly observed. When the train is approaching the compensation shaft (section D), a moderate overpressure is homogeneously established within the tunnel. Since the pressure is higher than outside, a net outflow is driven through the shaft. Complementarily, moderate and uniform velocity values in the range of $5 \mathrm{~m} / \mathrm{s}$ can be found inside the tunnel. Following, as the train advances in front of the shaft, a significant depression (-180 Pa) is progressively established inside the tunnel. Figure 10 shows the flow patterns for those positions where the piston effect is clearly manifested through the compensation shaft. Notice how this change in the flow pattern (revealed as an evolution from overpressure to underpressure within the tunnel) is manifested as an abrupt rise in the evolution of the DRS\#3 flow rate between 500 and $525 \mathrm{~m}$ in Figure 7. Complementarily, the plot in such figure reveals how at $550 \mathrm{~m}$ (section $\mathrm{E}$ ), the inflow is maximum, with a significant instantaneous flow rate. Moreover, the amplitude of this peak value is not only a function of the piston effect. For the case without mechanical extraction, the overall change from impulsion to suction values is the same as the one observed in the natural ventilation, thus indicating that the flow patterns are independent to the amount of air that is driven. However, for the other scenarios with mechanical ventilation, the amplitude is clearly modified with respect to the results from the natural ventilation. This is a consequence of the combination of the piston effect mechanisms and the mechanical extraction: as the volume of air extracted mechanically increases, the underpressure behind the train is higher and the amplitude of the piston effect is reinforced.

\section{Figure 10. Contour maps of static pressure inside the tunnel as the train passes through the draught relief shaft, for the over-ventilated scenario.}

After the train has passed DRS\#3, the pressure values start to recover. However, the pressure distribution is no longer uniform in the transversal section (see pressure maps on the left of Figure 11), so the pressure recovery will take place in a highly 
three-dimensional flow, which also confirms the need for a complete 3D modeling. Additionally, vector maps reveal a progressive reduction of the inflow through the compensation shaft when going from sections $E$ to $F$. When the train is close to the shaft, maximum velocities range from 3 to $5 \mathrm{~m} / \mathrm{s}$, while when the train leaves the tunnel they are reduced to moderate values between 1 and $3 \mathrm{~m} / \mathrm{s}$. This is also a consequence of the pressure recovery in that region. The flow under these conditions is highly perturbed, three-dimensional and with strong instabilities due to the associated drag provoked by the train displacement. Notice the lattice of vortices shed behind the train rear wake. These vortices are chopped by the jet impinging from the relief shaft (bottom vector map) and rolled up by the recirculation cells induced by the incoming flow expanding (recovering pressure) within the tunnel.

When the train is finally at Station 2, the inflow is significantly reduced (see ending zone in Figure 7) due to the reduction of the blockage coefficient within the station and due to the deceleration of the train itself.

This qualitative analysis of the flow patterns as the train advances between the stations has shown that the mechanical suction from the central shaft enhances the piston effect in the relief shafts. Additionally, Figure 7 revealed that in the case of natural ventilation, an instantaneous flow rate of $44,380 \mathrm{~m}^{3} / \mathrm{h}$ (approximately a thirty percent of the typical inflow introduced at each station) can be easily established by the piston effect. To provide a more comprehensive overview, Table 3 summarizes the more relevant numbers concerning the influence of the piston effect on the different tunnel ventilation scenarios. The first column shows how the instantaneous peak value is increased as the mechanical extraction is also raised, while in the second column these maximum flowrates are compared to the constant inflows of $120,000 \mathrm{~m}^{3} / \mathrm{h}$ per station. Notice that in all the ventilation conditions, the piston effect provides instantaneous values higher than one third of those $120,000 \mathrm{~m}^{3} / \mathrm{h}$.

\section{Figure 11. Flow conditions at sections $E$ and $F$ for the over-pressure ventilation case. Evolution of the train wake under non-uniform pressure gradients.}

Additionally, the difference between suction and impulsion flowrates in the relief shaft (third column) has been compared with the total outflows imposed mechanically in the tunnel (forth column). In this case, the impact of the piston effect is progressively decaying as the total amount of mechanical flows increases. Whatever the case, the percentage is remarkably high with values ranging between 25 and $50 \%$ depending on the mechanically-driven airflows. Therefore, it can be concluded that both suctions provoked by the piston effect and the mechanical extraction are

superimposed, enhancing the global ventilation towards the station where the train is heading up to. Logically, as the mechanical ventilation is increased, the piston effect is less relevant. Although these are instantaneous values, their magnitudes advise its introduction as an additional element in the regular design of ventilation systems in subway networks. 
Table 3. Influence of the piston effect on the airflows in DRS\#3 as a function of the ventilation conditions. Ratios respect station inflow and central extraction.

\begin{tabular}{lcccc} 
Ventilation scenario & $\begin{array}{c}\text { Peak inflow } \\
\left(\mathrm{m}^{3} / \mathrm{h}\right)\end{array}$ & $\begin{array}{c}\text { Percentage- } \\
\text { to-station }\end{array}$ & $\begin{array}{c}\text { Global induced } \\
\mathrm{flow}^{[3]}\left(\mathrm{m}^{3} / \mathrm{h}\right)\end{array}$ & $\begin{array}{c}\text { Percentage-to- } \\
\text { extraction }\end{array}$ \\
\hline Natural ventilation & 44,380 & - & 60,480 & - \\
W/o mech. extraction & 39,000 & $32.5 \%$ & 60,620 & $50.5 \%$ \\
Infra-ventilation & 47,380 & $39.5 \%$ & 70,560 & $47.0 \%$ \\
Under-ventilation & 49,170 & $41.0 \%$ & 72,360 & $40.2 \%$ \\
Neutral ventilation & 53,230 & $44.4 \%$ & 76,100 & $31.7 \%$ \\
Over-ventilation & 69,420 & $57.9 \%$ & 87,190 & $24.2 \%$ \\
\hline${ }^{[1]}$ Computed as the maximum value at section "E" in Figure 7. \\
${ }^{[2]}$ Percentage of peak flow respect to constant inflow of $120,000 \mathrm{~m}^{3} / \mathrm{h}$ per station. \\
[3] Amplitude of piston effect (Difference between sections E and D for each condition in Figure 7). \\
${ }^{[4]}$ Percentage of the amplitude with respect to each mechanical extraction.
\end{tabular}

Estimation of additional flow rate induced by train-motion. Table 3 shows an evident beneficial influence of the piston effect on the flow rates established through the draught relief shafts. However, in order to provide a better estimation of the energy amount that can be saved using this effect, it is better to analyze the flow rates inside the tunnel, because that it is the element susceptible of ventilation. Moreover, it is also convenient to convert the instantaneous flow rates shown in Figure 7 (and even the averaged values computed from the areas under the curves) into real "extended" flow rates, providing a long-term averaged value, where the number of trains running in the tunnel per hour is accounted for. This is because those instantaneous and train cycle-averaged flow rates obtained in the simulation are only present during the train motion (42 s), ceasing their impact until the next train arrives to Station 1 (typically 6-8 minutes later). Consequently, Table 4 computes the differential flow rates established in the tunnel for all the scenarios simulated (third column). A more realistic indicator of the overall mean airflow provided by the piston effect is obtained when this differential value is extended calculating the volume of air ventilated by the trains per hour, considering a frequency of 10 trains per hour (see forth column). Long-term averaged values in the range of $10,000 \mathrm{~m}^{3} / \mathrm{h}$ are estimated for the highest ventilation conditions. Finally, these values are compared to the mechanically-driven global flow rates, quantifying the percentage of ventilation flow rate gained with the piston effect with respect to the mechanical ventilation in the system (fifth column). Alternatively, this can be seen as an estimation of the energy consumption that could be saved for each scenario. Savings in the order of $2.5-3 \%$ can be given as a reference value for subway designers and operators.

At this point, a holistic approach would be of interest for subway designers to reduce energy consumptions for the whole system. In practice, this is a very complex analysis because it must consider the costs associated to traction power (in order to modify/increase the frequency of the trains) with respect to the attained ventilation reduction (including number of fan units and operating layouts). Also, the construction of additional shafts would be another possibility as a passive improvement of the system. Moreover, the particular characteristics of the subway are also an essential 
factor to provide a well-adjusted conclusion. In any case, this will require more insight, going beyond the scope of the paper (simulation of the train induced air flows in tunnels and stations in a 3D fashion and estimation of ventilation enhancements). As previously discussed, the CFD methodologies should be oriented towards the calibration of 1-D tools (such as SES, Thermotun or IDA Tunnel), which in turn are more appropriate for the analysis of a complete database (different tunnel and station geometries, parameters and so on).

Table 4. Influence of the piston effect on the airflows inside the tunnel as a function of the ventilation conditions. Percentage of ventilation given by the train motion in the long-term with respect to the overall mechanical ventilations.

\begin{tabular}{|c|c|c|c|c|c|}
\hline $\begin{array}{c}\text { Ventilation scenario } \\
\text { (1 train) }\end{array}$ & $\begin{array}{l}\text { Initial flow } \\
\text { rate in } \\
\text { tunnel }{ }^{[1]} \\
\left(\mathrm{m}^{3} / \mathrm{h}\right)\end{array}$ & $\begin{array}{c}\text { Average } \\
\text { during train } \\
\text { motion } \\
\left(\mathrm{m}^{3} / \mathrm{h}\right)\end{array}$ & $\begin{array}{l}\text { Differential } \\
\text { flow rate in } \\
\text { tunnel }{ }^{[3]} \\
\left(\mathrm{m}^{3} / \mathrm{h}\right)\end{array}$ & $\begin{array}{c}\text { Extended } \\
\text { flow rate }{ }^{[4]} \\
\text { (averaged } \\
\mathrm{m}^{3} / \mathrm{h} \text { ) }\end{array}$ & $\begin{array}{l}\text { Percentage- } \\
\text { to-total } \\
\text { mechanical } \\
\text { ventilation }^{[5]}\end{array}$ \\
\hline Natural ventilation & 0 & 6,800 & 6,800 & 790 & - \\
\hline W/o mech. extraction & $-8,600$ & 13,000 & 21,600 & 2,520 & $2.1 \%$ \\
\hline Infra-ventilation & 42,000 & $-31,300$ & 73,300 & 8,550 & $3.2 \%$ \\
\hline Under-ventilation & 56,700 & $-20,500$ & 77,200 & 9,010 & $3.0 \%$ \\
\hline Neutral ventilation & 86,400 & -400 & 86,800 & 10,100 & $2.8 \%$ \\
\hline Over-ventilation & 179,600 & 80,500 & 99,100 & 11,600 & $2.4 \%$ \\
\hline
\end{tabular}

${ }^{[1]}$ Volumetric flow rate in the tunnel at steady conditions before the train-motion.

${ }^{[2]}$ Average flow rate in tunnel during train motion.

${ }^{[3]}$ Difference in ventilation due to the piston effect (Mean flow rate gained during train motion $-42 \mathrm{~s}$ ).

${ }^{[4]}$ Equivalent mean flow rate gained due to the piston effect, considering a typical schedule of 10 trains per hour.

${ }^{[5]}$ Percentage of ventilation gained with the piston effect respect to the total mechanical ventilation $\left(120,000 \mathrm{~m}^{3} / \mathrm{h}\right.$ inflow in the station and the mechanical extraction in every case).

Two trains crossing halfway. To conclude this section, the unsteady flow rates generated by two trains crossing halfway are presented below (Figure 12). The information presented is analogous to Figure 7 . In the $x$-axis, both the distance travelled by the first train going from station 1 to station 2 and the time elapsed have been maintained. As before, the $y$-axis shows the volumetric flow rate through the relief shaft DRS\#3, with positive values indicating entering airflows. Globally, the flow behavior is similar for all the ventilation systems considered. Between sections B and $\mathrm{C}$, the overpressure associated to the second train approaching DRS\#3 induces an outflow which is more evident in the case of natural ventilation. After section $C$, there is a slope change associated to the end of the trains acceleration, followed by a plateau evolution from sections $D$ to $F$. This zone of nearly constant flow rate is due to the balance of the suction effects of the second train with the flow induced by the first train. The mean value of each ventilation condition in that central region is equivalent to the initial conditions (no trains running) but damped due to the blockage effect of the trains inside the tunnel. Finally, the flow conditions between sections $\mathrm{F}$ to $\mathrm{H}$ are similar to previous results in Figure 7, but with a significant increase of the peak values at section $\mathrm{G}$. 
As expected, the amplitudes associated to each peak are different (see the differences between sections $B$ and G). Moreover, this difference is even higher as the mechanical ventilation is increased. In particular, the piston effect of the second train is opposed to the suction of the central ventilation, with a maximum reduction of nearly a $40 \%$ respect to the no-ventilation case (Table 5). On the contrary, the piston effect of the first train (going from station 1 to station 2) is a coincident contributor with respect to the mechanical suction, so the overall ventilation can be enhanced by $20 \%$ (see Table 5).

Figure 12. Evolution of the flow rate through DRS\#3 as a function of the ventilation conditions (results for two trains crossing halfway).

Finally, the outgoing flow rates in DRS\#3 are listed in the third column of the table. These values allow a direct comparison with respect to the case when only one train is travelling through the tunnel. In addition, the increment in percentage with respect to the former case is also given (last column). Notice that there is an amplification of the piston effect of the first train, whatever case is considered. This means that despite of the competitive effects of the second train, the increment in the tunnel blockage is the key factor in the increase of the overall influence of the piston effect in the ventilation conditions. In particular, typical values ranging from 20 to $30 \%$ can be found, with a lower influence as the mechanical ventilation is more important.

Table 5. Influence of two piston effects on the airflows inside DRS\#3 as a function of the ventilation conditions. Ratios respect station inflow and central extraction.

\begin{tabular}{|c|c|c|c|c|}
\hline Ventilation scenario & $\begin{array}{l}\text { Flow } \\
\text { increase }{ }^{[1]} \text { in } \\
\text { train } 1\end{array}$ & $\begin{array}{l}\text { Flow } \\
\text { increase } \\
\text { in train } 2\end{array}$ & $\begin{array}{c}\text { Global induced } \\
\text { flow }{ }^{[3]} \text { for train } 1 \\
\left(\mathrm{~m}^{3} / \mathrm{h}\right)\end{array}$ & $\begin{array}{l}\text { Maximum } \\
\text { increase with } \\
\text { two trains }^{[4]}\end{array}$ \\
\hline Natural ventilation & - & - & 88,560 & $31.7 \%$ \\
\hline W/o mech. extraction & $0.0 \%$ & $0.0 \%$ & 89,670 & $32.4 \%$ \\
\hline Infra-ventilation & $11.7 \%$ & $-16.6 \%$ & 98,960 & $28.7 \%$ \\
\hline Under-ventilation & $13.7 \%$ & $-19.8 \%$ & 100,690 & $28.1 \%$ \\
\hline Neutral ventilation & $15.6 \%$ & $-26.3 \%$ & 102,380 & $25.7 \%$ \\
\hline Over-ventilation & $19.8 \%$ & $-39.2 \%$ & 106,060 & $17.8 \%$ \\
\hline
\end{tabular}

Assessment of the attenuation effect associated to Draught Relief Shafts. Another important issue is the analysis of the attenuation effect that relief shafts achieve over the flow conditions in the stations. The interest is to know if the platform for the passengers could be isolated with respect to the aerodynamic effects established in the tunnel. To provide some information, the evolution of the pressure and the 
velocity values in three different points along the tunnel has been monitored for two ventilation conditions in Figure 13.

The first point (P1 - solid thick lines) is located before the relief shaft (see the sketch in Figure 13) approximately $40 \mathrm{~m}$ ahead. The second point (P2 - solid narrow lines) is just inside the station (15 m behind the DRS\#3 section), while the last one (P3 - dashed lines) has been picked $90 \mathrm{~m}$ behind the relief shaft, well inside the station. The figure shows the pressure and velocity variations in the points as a function of the distance travelled by the train for the over-ventilated (dark lines) and w/o mechanical ventilation (grey lines) cases.

On the one hand, P1 experiences a great influence of the piston effect as shown in the sharp changes for both pressure and velocity plots after $450 \mathrm{~m}$. Minimum depressions of $-140 \mathrm{~Pa}$ and maximum peaks around 5-6 m/s can be easily reached. On the other hand, both points P2 and P3 are unaffected by the piston effect with moderate to low impacts of roughly $20 \mathrm{~Pa}$ in pressure and insignificant changes in velocity (from 1 to $2 \mathrm{~m} / \mathrm{s}$ ). It is also remarkable how the velocity at P3 remains practically constant, which is essential to preserve calmed regions of the airflow in the passengers platform. Notice that the ventilation conditions are not a relevant parameter for these evolutions.

When the case with two trains is studied (Figure 14), the double-peaked distributions reveal the influence of both piston effects. Once again, only at P1 the pressure fluctuations are really noticeable, with maximum values of $350 \mathrm{~Pa}$ associated to the second train. There is an attenuated region between the piston effects which appears to be in concordance with the central plateau previously discussed in Figure 12. Besides, pressure values at $\mathrm{P} 2$ and $\mathrm{P} 3$ remain practically atmospheric, confirming the effectiveness of the shaft relief. More significant are the diagrams for the velocity values with both contributions of the piston effect raising instantaneous peaks. Notice that P2 presents some high numbers due to inertial effects in the flow. Maximum values are lower than those observed in the case of just one train, but there is more instability as a consequence of the major complexity of the flow. Nevertheless, from the results shown for point P3, it is clear that the relief shaft attenuates all the unsteady flow coming from the piston effects within the tunnel, in all the ventilation conditions studied.

Figure 13. Attenuation effect of DRS\#3 for the case with one train. Figure 14. Attenuation effect of DRS\#3 for the case with two trains.

A few words on turbulence. The air stream turbulence is also an important parameter to describe the quality of the incoming, refreshing flow in the stations. Therefore, the effectiveness of the relief shafts can also be analyzed in terms of attenuation regarding turbulent fluctuations of the flow.

To illustrate the turbulence levels induced by the piston effect, a representation of the velocity fluctuations in the vicinity of the draught relief shaft is shown in Figure 15 for the over-ventilation case. Since natural ventilation presents a quasi-stationary scenario for the velocity fields, with turbulence intensities extremely low, this indicator will be only relevant for those cases with mechanical ventilation. These fluctuations 
are computed from the instantaneous maps of turbulence kinetic energy, k, (given by the $k-\varepsilon$ turbulence model), assuming isotropy of the turbulent scales $\left(u^{\prime} \sim v^{\prime} \sim w^{\prime}\right)$, so $k$ $=0.5\left(u^{\prime 2}+v^{\prime 2}+w^{\prime 2}\right)$ can be approximated by $k \sim 3 u^{\prime 2} / 2$. Thus, a characteristic level for these fluctuations is calculated as $\mathrm{u}^{\prime} \sim(2 \mathrm{k} / 3)^{0.5}$.

The first map shows the velocity fluctuations as the train is passing through DRS\#3. The train wake is a major mechanism of turbulent instabilities, especially when compared to the fully-calmed regions observed in the station (blue zones ahead of the train). Also noticeable is the turbulence associated to the impinging flow coming from the inflow at the station, just right in front of the train at this location. In particular, the flow generated by the stagnation conditions of the train interacts with the incoming flow from the shaft, generating turbulence in the shear layers of both stream flows. This is shown in the annexed sketch where the two air currents collide increasing the turbulence intensity. Once the train has completely passed the relief shaft (map on the bottom), the sudden depression induced by the train tail will help to reduce the instantaneous turbulence levels (though locally the wake turbulence experiences a certain reinforcement because the flow in the DRS\#3 is inverted).

To conclude this section, a quantitative description of these flow patterns is provided in Figure 16, where instantaneous turbulence intensities are monitored inside the station (point $\mathrm{P} 2$, nearby the station platform). The turbulence intensity is defined as the percentage ratio of the velocity fluctuations with respect to the local time-resolved velocity, according to the expression: $\mathrm{Tu}[\%]=100 \mathrm{u}^{\prime} / U$. Typical values in the range of 5 to $15 \%$ are considered acceptable conditions for the passengers' comfort [33, 34].

Figure 15. Turbulent fluctuations induced by the passing train in DRS\#3.

The maximum turbulence intensity is observed when the train is approaching the monitored point. After the flow is inverted, the depression established controls the turbulence level and a sudden reduction is developed. When the train arrives at the platform, there is also a final increase that decays progressively due to the train deceleration. Figure 16 also shows the results obtained in the case of two trains crossing inside the tunnel. The turbulence associated to the first piston effect is significantly lower, while the second provokes turbulence levels in concordance with the single train results.

Figure 16. Turbulence intensities provoked by the piston effect.

\section{Conclusions}

This paper presents a numerical methodology based on a dynamic mesh technique to properly simulate the influence of the piston effect in the longitudinal ventilation systems of subway tunnels. A wide number of different ventilation scenarios and train configurations have been analyzed to assess the effectiveness of draught relief shafts 
in the attenuation of piston effects. Contour maps of velocity fields and pressure distributions in significant sections have been obtained to describe the unsteady, three-dimensional flows associated to the piston effect. Moreover, the global results have been compared with a 1-D simulation and the CFD computations have been proposed as a calibration tool for those simplified, but faster, methodologies. Additionally, instantaneous flow rates and long-term "extended" values have been analyzed in compensation shafts and through the tunnel to quantify the potential of the piston effect to enhance the ventilation system.

It has been demonstrated that the ventilation conditions in a subway system are clearly conditioned by the piston effect. Additionally, the number of running trains is also a significant contributor to the behavior of the ventilation system. It is concluded that the amplitude of the piston effect is influenced by the central mechanical extraction. The instantaneous flow rate driven by the piston effect can be as high as a $50 \%$ of the total flow rate generated in the ventilation system, depending on the mechanical extraction imposed. Whatever the case, and compared to typical stations inflows, the piston effect involves a significant amount of air renovation that should be taken into account in the design of ventilation protocols.

In order to benefit from the pressure fluctuations induced by train movement in the best manner, the ventilation should be operated so that the train-induced air flows are supported by mechanical ventilation. This might require train position and train direction dependent ventilation. Regarding the civil layout, passive shafts in the middle of tunnels are most efficient to use the train induced pressure changes for airexchange between the tunnel and the outside (at least for systems without full-height platform screen doors). Though it is not the scope of the paper, at the same time, these tunnel shafts reduce traction power demands of trains most efficiently.

In particular, it has been estimated an overall energy saving in the order of 2.5 to $3 \%$ taking into account the airflow caused by the train-motion. This percentage is increased as the mechanical ventilation is progressively reduced. Depending on the train schedules and frequencies, this amount can substantially change, being a function of the number of piston effects per hour. Another important parameter is the blockage factor that conditions the "strength" of the piston effect. Comparisons of the 3-D computations with the 1-D modeling have shown how the impact of this parameter is basic in the establishment of the pressure rise provoked by the train motion. In the case of single-track tunnels (with larger blockages), a higher influence of the piston effect is expected, providing even better ratios for energy savings than those obtained with the present geometry. When two trains crossing halfway are travelling in the tunnel, the enhancement of the ventilation is between 20 to $30 \%$ with respect to the case with just one train, depending also on the mechanical extraction.

Typical sections and layouts of draught relief shafts in modern subways have demonstrated their ability to attenuate and isolate the unsteady pulses of the piston effects, preserving calmed regions of air flow in the stations. Moreover, the homogeneity is remarkable in both the pressure and the velocity values achieved in the vicinity of the station platforms. This effectiveness has also been checked in terms of turbulent fluctuations of the flow, where moderate values in the range of $4-5 \%$ have been observed in the platforms during the train displacement. Only isolated turbulence peaks have been observed due to the instantaneous disturbance of the piston effect and they are small enough (about 16\%) not to compromise the 
passengers comfort in the stations. The attenuation of the relief shafts depends marginally on the ventilation system, and it is somewhat lower for two opposite trains than for a single train running in the tunnel.

\section{References}

[1] London Underground, Environment Report, 2006.

[2] Annual Report, TMB, Metro de Barcelona, 2010.

[3] Hu, S.-C., Tung, Y.-C., Hsu, M.-F., "Assesing the potentials of energy-saving strategies for an underground mass rapid transit system with platform doors", 2006, International Journal on Architectural Science, vol. 7 (3), pp. 67-76.

[4] Sustainable Energy mAnageMent for Underground Stations, SEAM4US Project, 2011, (http://seam4us.eu/)

[5] Hong, W., Kim, S., "A study on the energy consumption unit of subway stations in Korea", 2004, Building and Environment, vol. 39, pp. 1497-1503.

[6] Bopp, R., Hagenah, B., "Aerodynamics, ventilation and tunnel safety for high-speed rail tunnels", 2009, Gruner-GmbH.

[7] Lin, C-J., Chuah, Y.K., Liu C.-W., "A Study on Underground Tunnel Ventilation for Piston Effects Influenced by Draught Relief Shaft in Subway System", 2008, Applied Thermal Engineering, vol. 28(5-6), pp. 372-379.

[8] Yuan, F.D., You, S.J., "CFD Simulation and Optimization of the Ventilation for Subway Side-Platform", 2007, Tunnelling and Underground Space Technology, vol. 22(4), pp. 474-482.

[9] Krasyuk, A.M., Lugin, I.V., "Investigation of the Dynamics of Air Flows generated by the Disturbing Action of Trains in the Metro", 2007, Journal of Mining Science, vol. 43(6), pp. 655-661.

[10] Kim, J.Y., Kim, K.Y., "Effects of Vent Shaft Location on the Ventilation Performance in a Subway Tunnel", 2009, Journal of Wind Engineering and Industrial Aerodynamics, vol. 97(5-6), pp. 174-179.

[11] Kim, J.Y., Kim, K.Y., "Experimental and Numerical Analyses of Train-induced Unsteady Tunnel Flow in Subway", 2007, Tunnelling and Underground Space Technology, vol. 22(2), pp. 166-172.

[12] Huang, Y., Gao, W., Kim, C.N., "A Numerical Study of the Train-induced Unsteady Airflow in a Subway Tunnel with Natural Ventilation Ducts using the Dynamic Layering Method", 2010, Journal of Hydrodynamics B, vol. 22(2), pp. 164-172.

[13] Ke, M.-T., Cheng, T.-C., Wang, W.-P., "Numerical Simulation for Optimizing the Design of Subway Environmental Control System", 2002, Building and Environment, vol. 37(11), pp. 1139-1152.

[14] Yang, H., Jia, L., Yang, L., "Numerical Simulation of the Impact of Both Air Conditioning System and Trains Movement on Platform Air Temperature Distribution", 2008, Proceedings of the ASME 2008 Heat Transfer Summer Conference, ASME Paper HT2008-56201.

[15] El-Bialy, E.M., Khalil, E.E., "Experimental and Numerical Investigation of Indoor Environmental Quality in a Subway Station", 2010, Proceedings of the Tenth International Congress of Fluid Dynamics, Paper ICFD10-EG-3160. 
[16] Gawthorpe, R., "Pressure Effects in Railway Tunnels", April-2010, Rail International.

[17] Colella, F., Rein, G., Torero, J.L., Borchielline, R.A., "A Novel Multiscale Methodology for Simulating Tunnel Ventilation Flows during Fires", 2010, Fire Technology, vol. 47(1), pp. 221-253.

[18] Galdo-Vega, M., Argüelles, K.M., Fernández Oro, J.M., Ballesteros, R., Santolaria, C., "Numerical 3D Simulation of a Longitudinal Ventilation System: Memorial Tunnel Case", 2008, Tunnelling and Underground Space Technology, vol. 23(5), pp. 539-551.

[19] Ballesteros-Tajadura, R., Santolaria-Morros, C., Blanco-Marigorta, E., "Influence of the Slope in the Ventilation Semi-transversal System of an Urban Tunnel", 2006, Tunnelling and Underground Space Technology, vol. 21(1), pp. 21-28.

[20] Hagenah, B., Vardy, A., Reinke, P., "Effectiveness of Pressure Relief Shafts - Full Scale Assessment", 2006, Proceedings of the 12th International Symposium on Aerodynamics and Ventilation of Vehicle Tunnel, Portoroz, Slovenia.

[21] Chen, T.Y., Lee, Y.T., Hsu, C.C., "Investigations of Piston-Effect and Jet Fan-Effect in Model Vehicle Tunnels", 1998, Journal of Wind Engineering and Industrial Aerodynamics, vol. 73(2), pp. 99-110.

[22] Hai-Tao, B., "Study of Piston Wind in Subway Tunnel based on Numerical Simulation", 2010, Proceedings of the 3rd IEEE International Conference on Computer Science and Information Technology (ICCSIT), Chengdu, China.

[23] Karaslan, S., Yuncel, N., Dinler, N., "Piston Effect on Fire-Induced Flow and Human Comfort in an Underground Transportation System Station Model", 2010, International Virtual Journal for Science, Technics and Innovations for the Industry, vol. 8-9, pp. 17-21.

[24] Ping, L., Yunmei, P., Guangxuan, L., Jinhua, S., "Piston Effect and Piston Wind Velocity in the Subway Tunnel System by Shaft Exhaust Ventilation", 2006, Proceedings of the International Symposium on Progress in Safety Science and Technology, vol. VI, part A.

[25] Uystepruyst, D., Willian-Louis, M., Creusé, E., Nicaise, S., Monnoyer, F., “3D Numerical Prediction of the Pressure Wave generated by High-speed Trains entering Tunnels", 2011, Computers and Fluids, vol. 47(1), pp. 165-177.

[26] Wang, F., Wang, M., He, S., Debg, Y., "Computational Study of Effects of Traffic Force on the Ventilation in Highway Curved Tunnels", 2011, Tunneling and Underground Space Technology, vol. 26(3), pp. 481-489.

[27] Yang, K.H., Lee, S.K., "Experimental Validation of Tunnel Ventilation System under Emergency Operation", 2001, Proceedings of the ASHRAE Summer Meeting, Atlanta, USA.

[28] Yang, W.C., Peng, L.M., Wang, L.C., "Computation Simulation on Aerodynamic Characteristic of PSD in Subway Platform", 2009, Proceedings of the International Conference on Computer Engineering and Technology, vol. 2, pp. 395-398.

[29] Lau, B., Yau, R., “Tunnel Ventilation”, 2007, The Arup Journal, vol. 3, pp. 32-35.

[30] Yuncel, N., Berberoglu, M.I., Karaslan, S., Dinler, N., "Experimental and Numerical Simulation of Fire in a Scaled Underground Station", 2008, World Academy of Science, Engineering and Technology, vol. 40, pp. 309-314. 
[31] Yan, W., Naiping, G., Lihui, W., Xiping, W., "A Numerical Analysis of Airflows Caused by Train-Motion and Performance Evaluation of a Subway Ventilation System", 2013, Indoor and Built Environment, in-press.

[32] EN 14067-3:2003, "Railway applications - Aerodynamics. Part 3: Aerodynamics in Tunnels", 2003.

[33] Loomans, M.G.L.C., Mook, F.J.R. "Survey on Measuring Indoor Airflows", 1995, FAGO Report 95.25.W, Eindhoven University of Technology, Eindhoven, The Netherlands.

[34] Gao, N.P., Zhang, H., Niu, J.L., "Investigating Indoor Air Quality and Thermal Comfort Using a Numerical Thermal Manikin", 2007, Indoor and Built Environment February, vol. 16(1), pp. 7-17. 

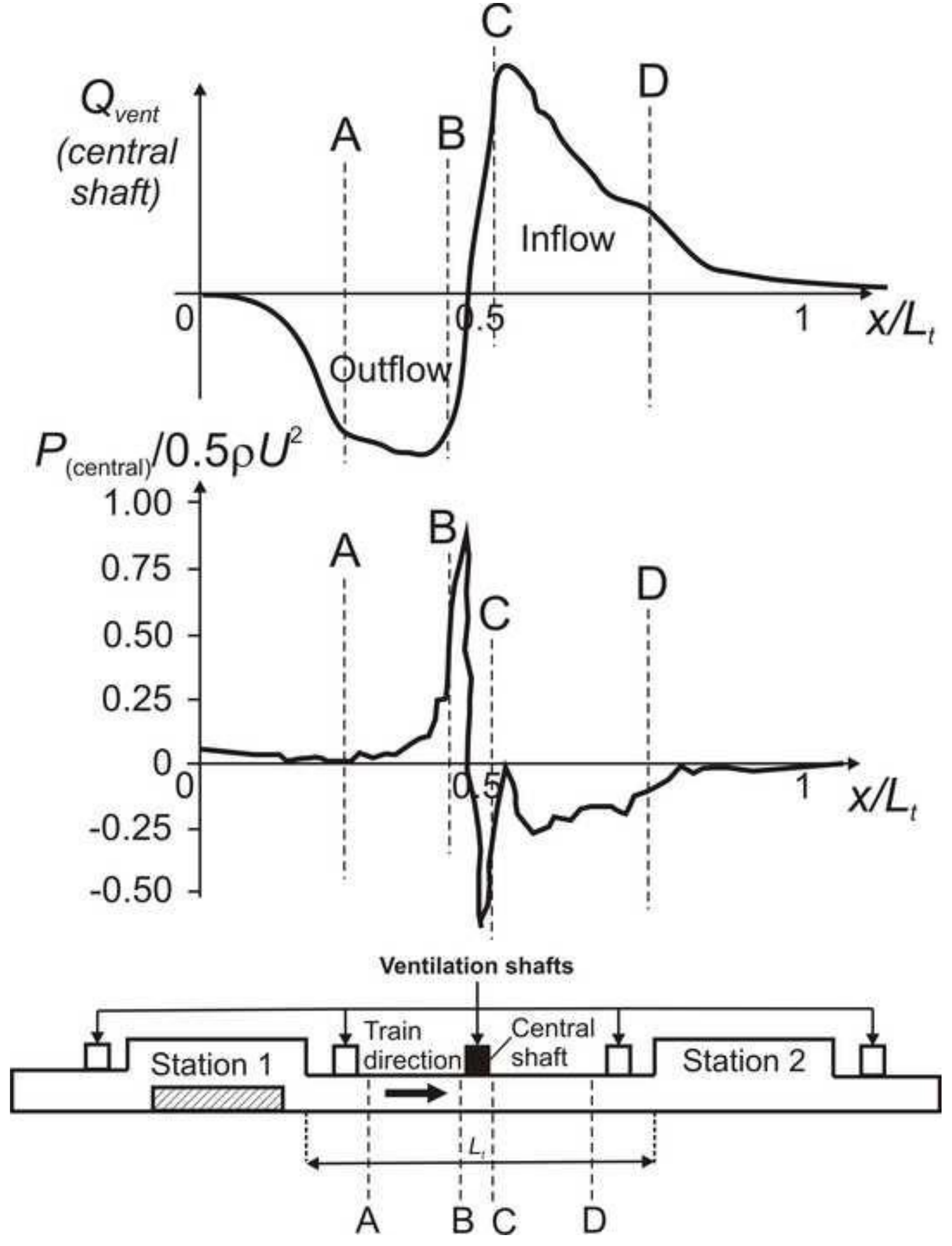
Draught Relief Shafts (DRS)

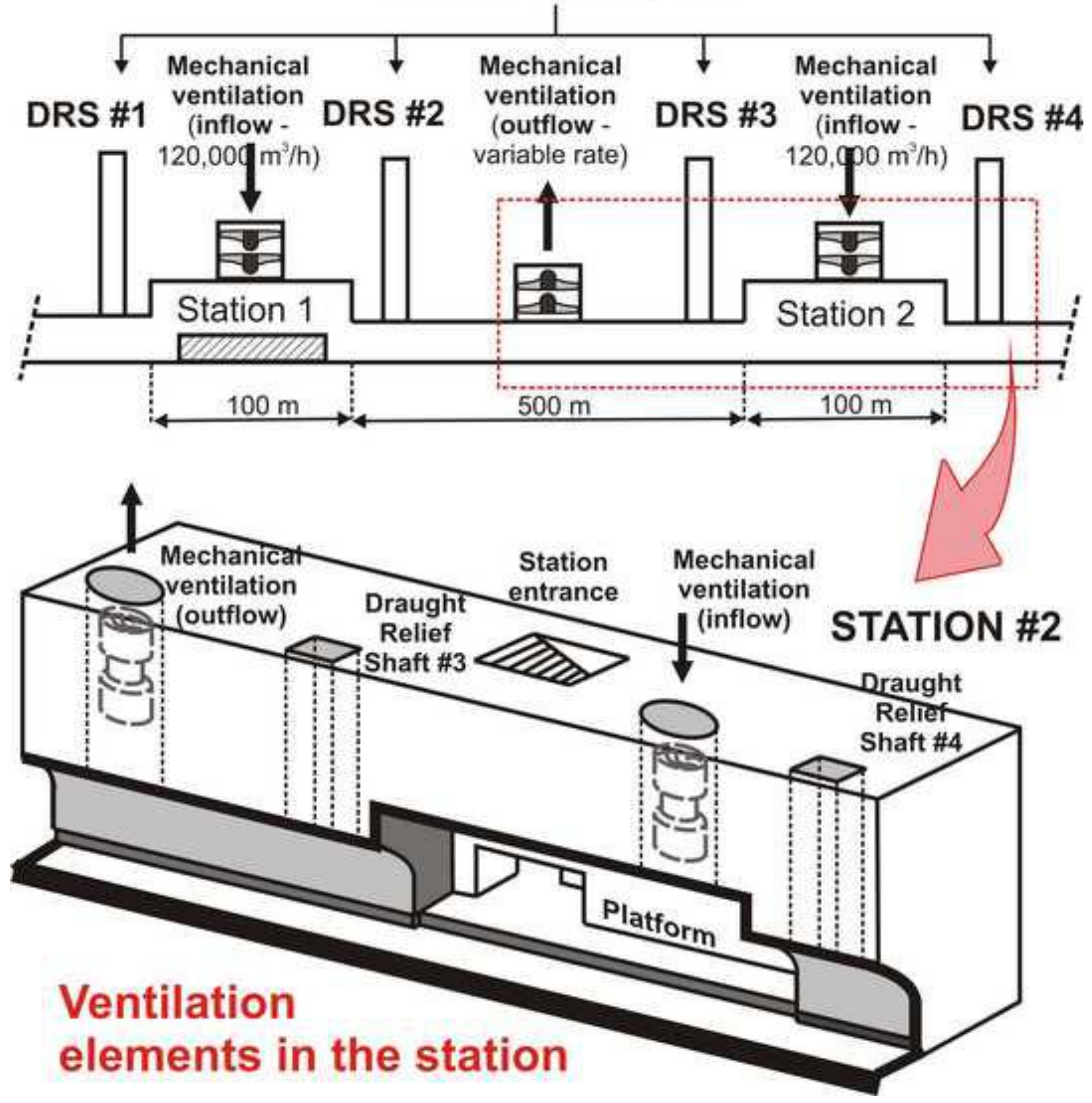



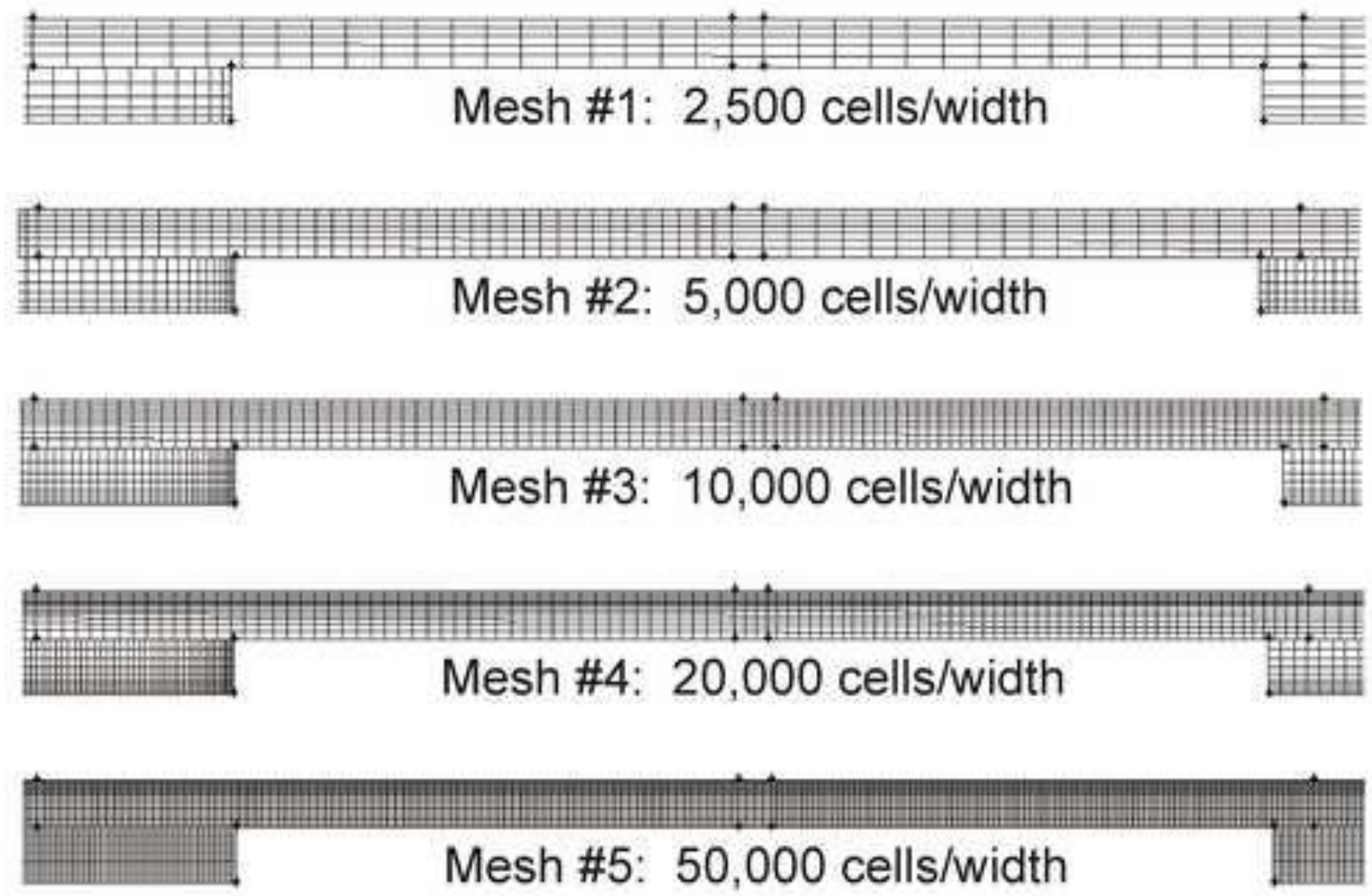

DRAUGHT RELIEF SHAFT \#3

VELOCITY IN THE TUNNEL
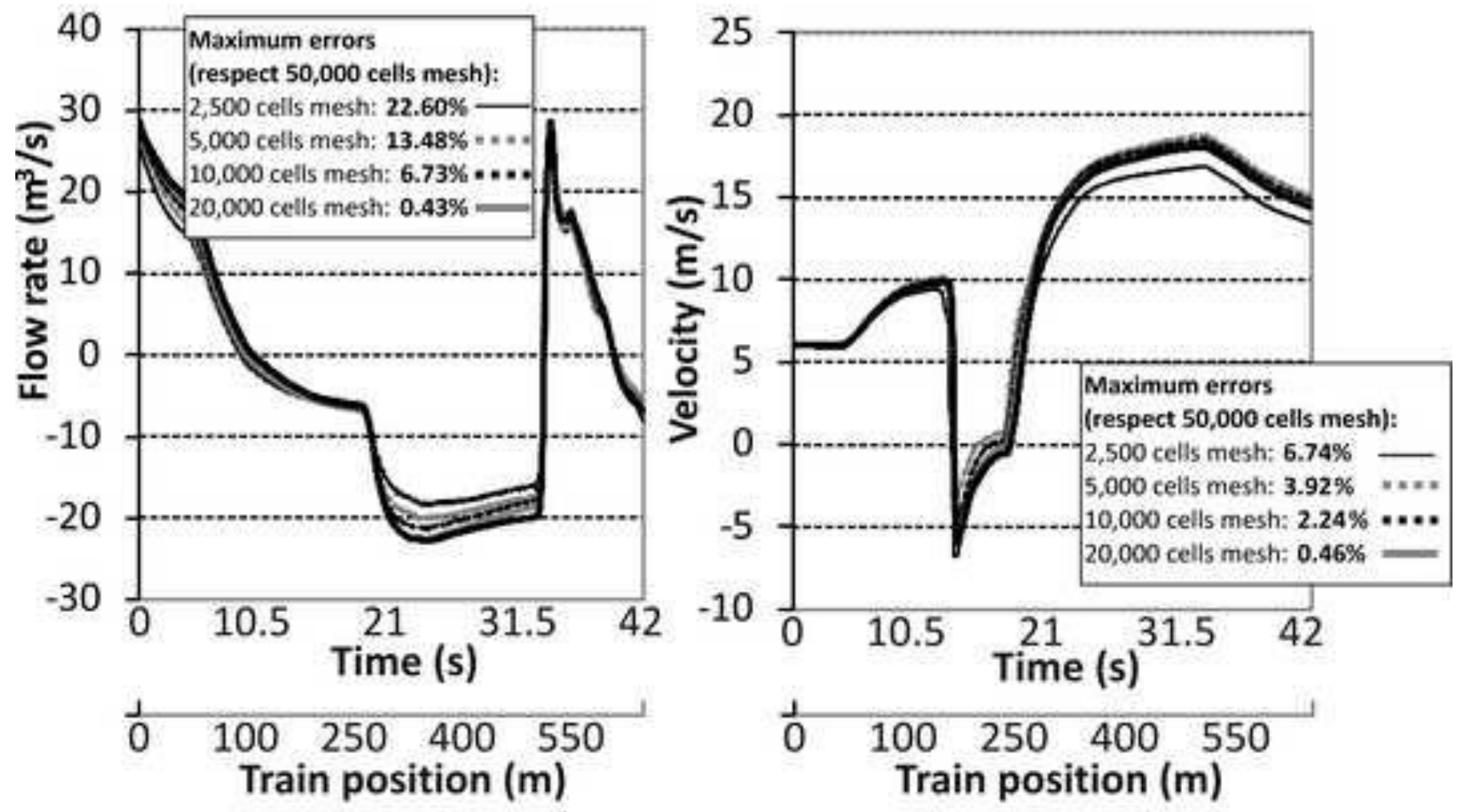


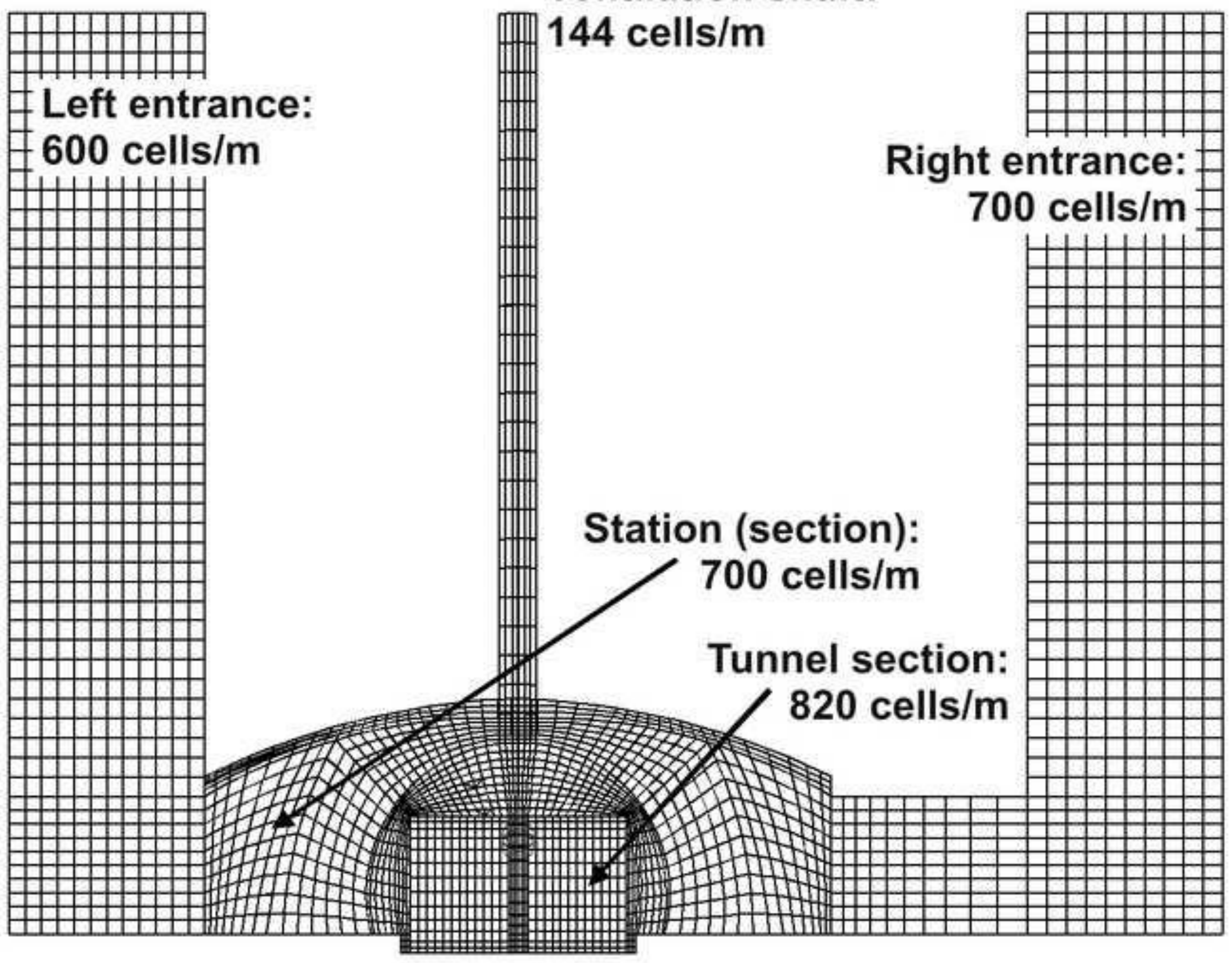

Ventilation shaft:

\section{4 cells $/ \mathrm{m}$}

Station (section): 700 cells $/ \mathrm{m}$

Tunnel section: $820 \mathrm{cells} / \mathrm{m}$ cells/m.

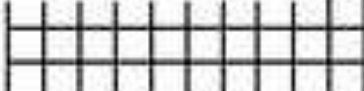
\begin{tabular}{lllllllll}
1 & & & & & & & & \\
\hline
\end{tabular} \begin{tabular}{llllllll}
\hline & & & & & & & \\
\hline
\end{tabular}

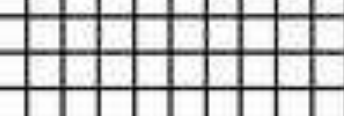
\begin{tabular}{lllllllll}
\hline & & & & & & & & \\
\hline
\end{tabular} ( ( D ( (1)

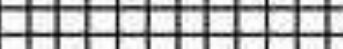
(1)

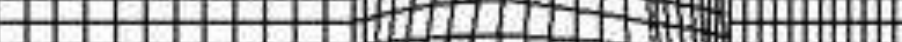




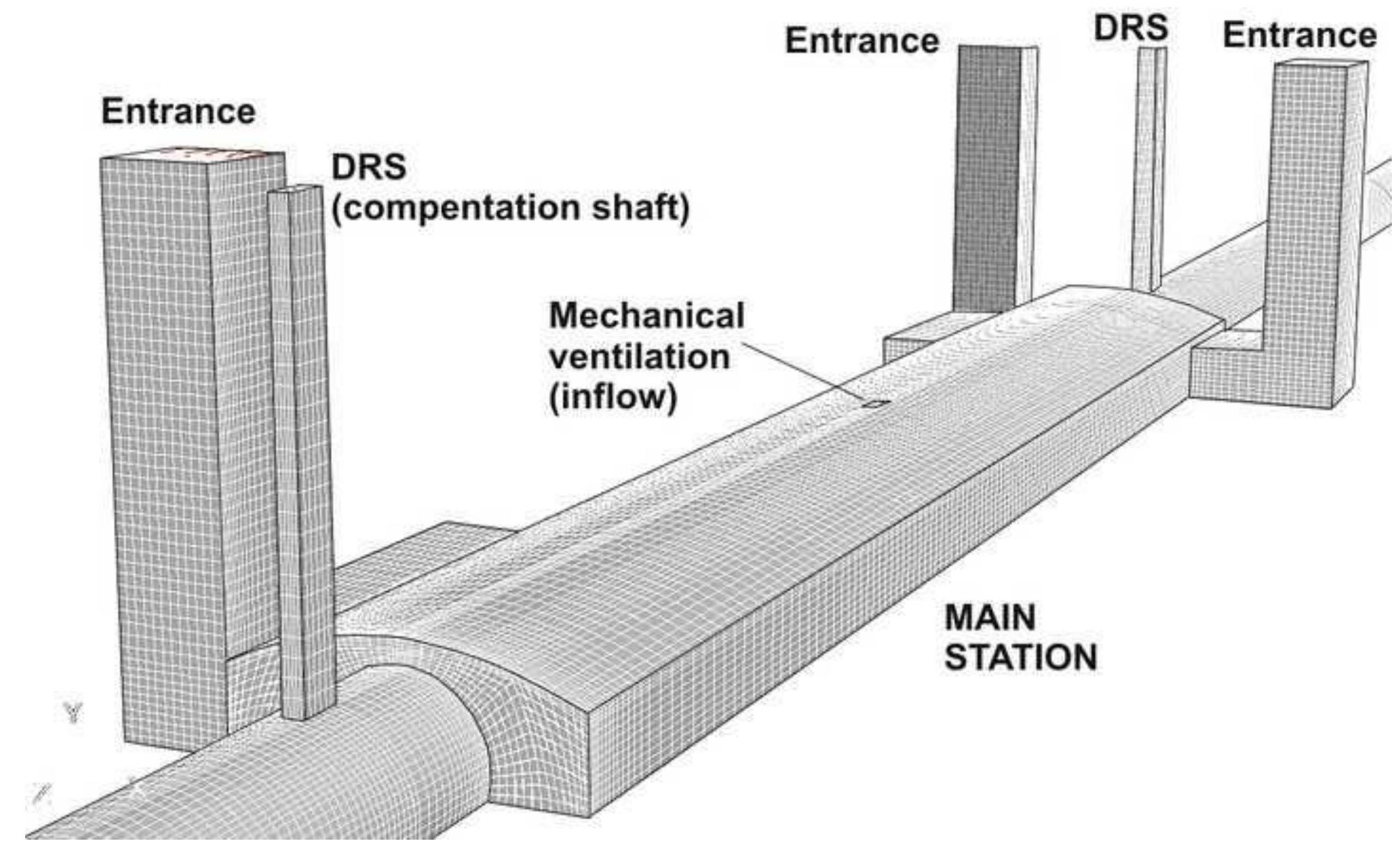

\section{Entrance}

DRS ventilation (inflow)

\section{MAIN STATION}

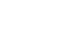




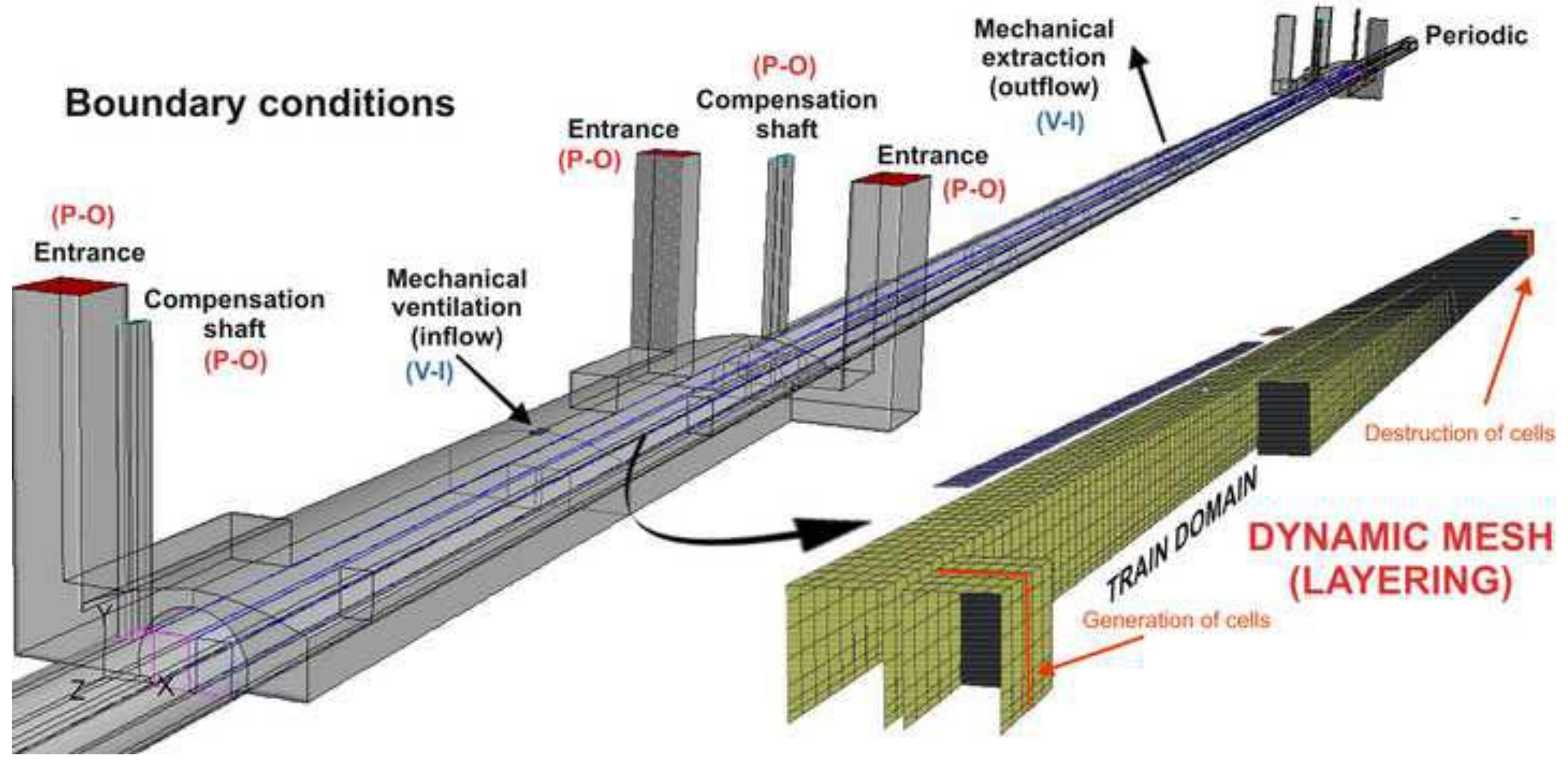

Boundary conditions

$$
\text { (P-O) }
$$
(inflow)

$(\mathrm{V}-\mathrm{I})$

Generation of cells

(LAYERING)
Mechanical
extraction flow

\section{Entrance} shaft

Mechanical

( 

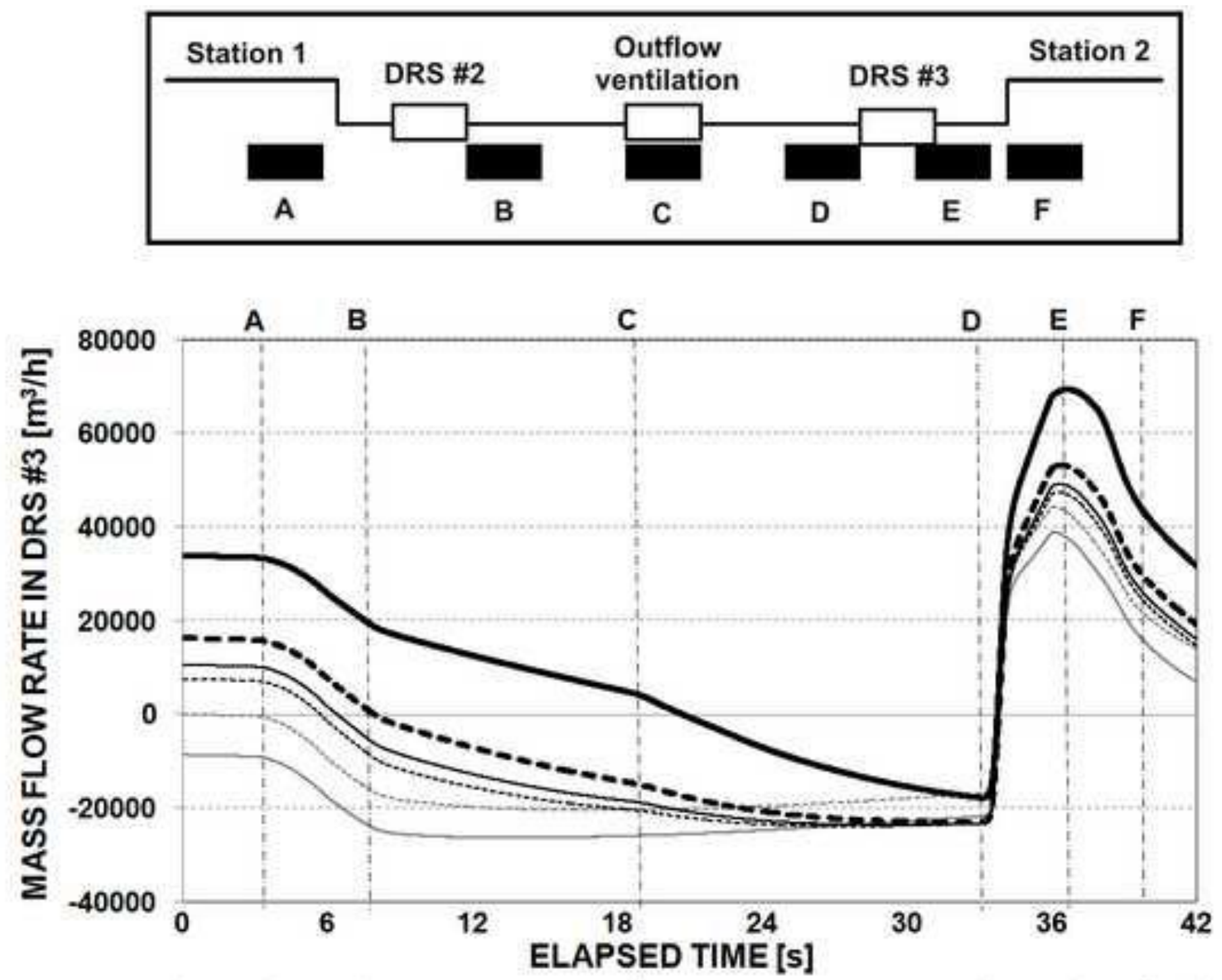

$\begin{array}{llllllllllllllll}0 & 11 & 42 & 88 & 134 & 179 & 225 & 271 & 317 & 363 & 409 & 454 & 500 & 546 & 584 & 600\end{array}$ TRAVELLED DISTANCE [m] 
Click here to download high resolution image
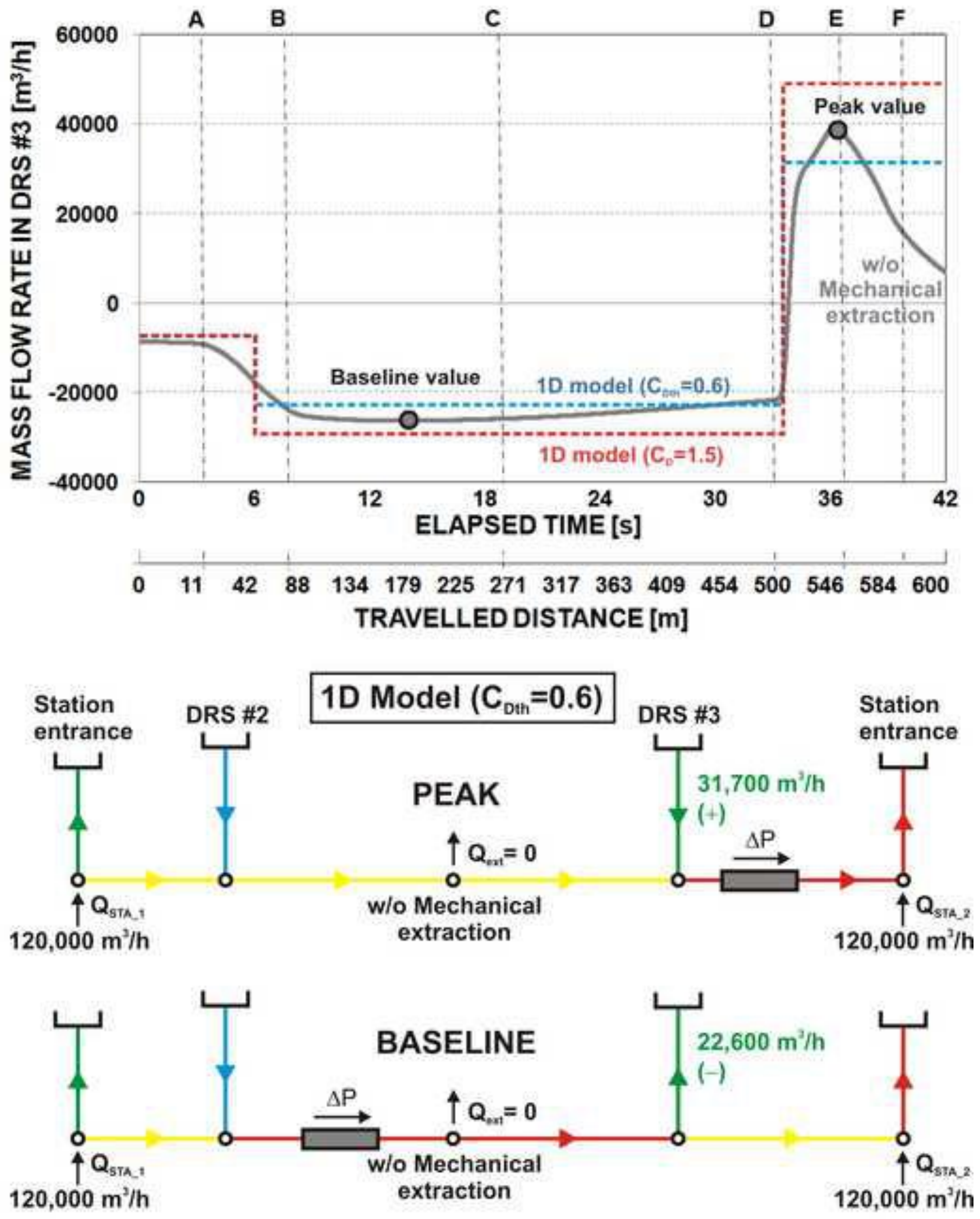

Flow rate $\left(\mathrm{m}^{3} / \mathrm{h}\right)$

$\begin{array}{llllll}250,000 & 125,000 & 50,000 & 20,000 & 8,000 & 0\end{array}$ 

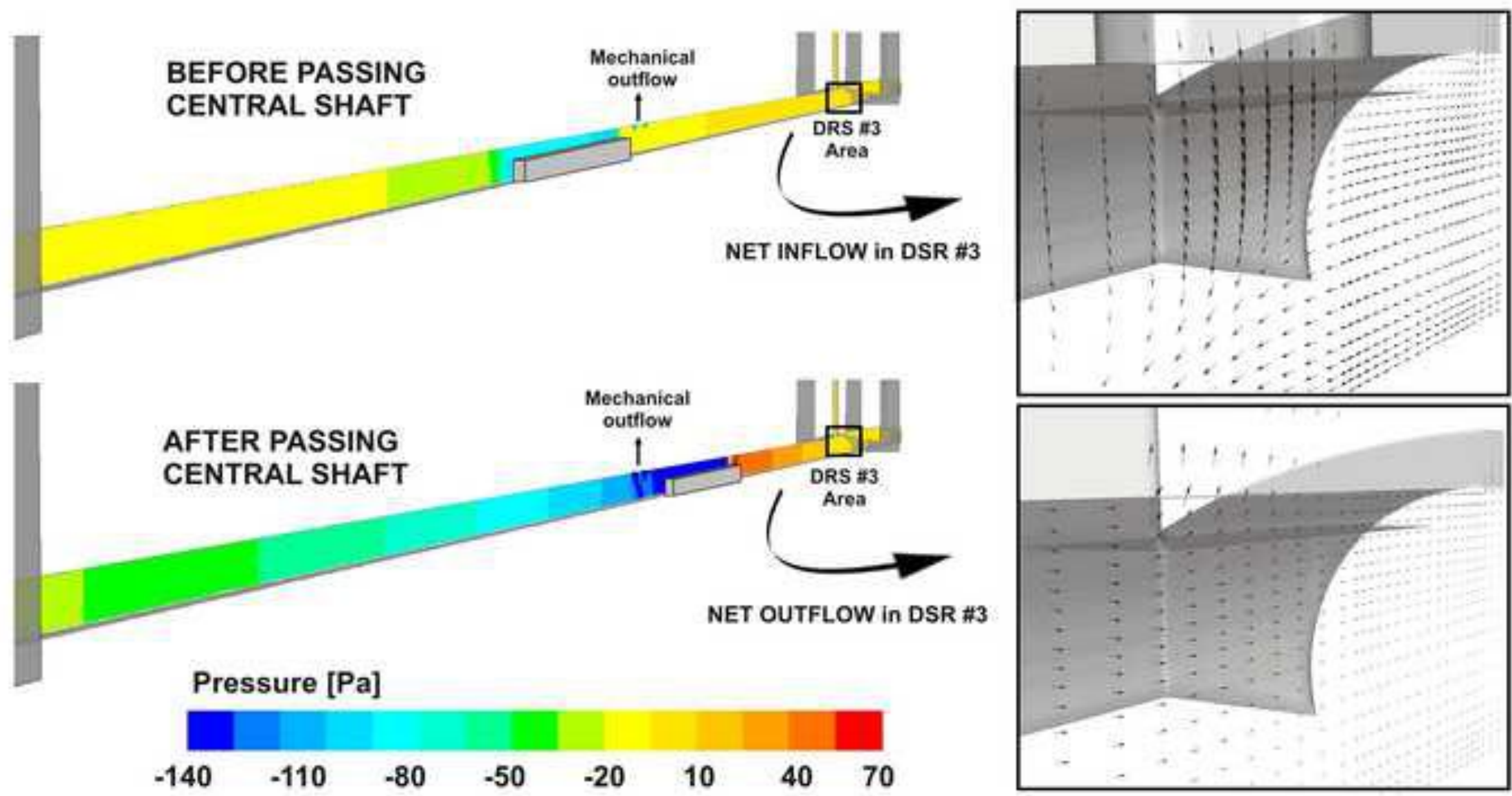

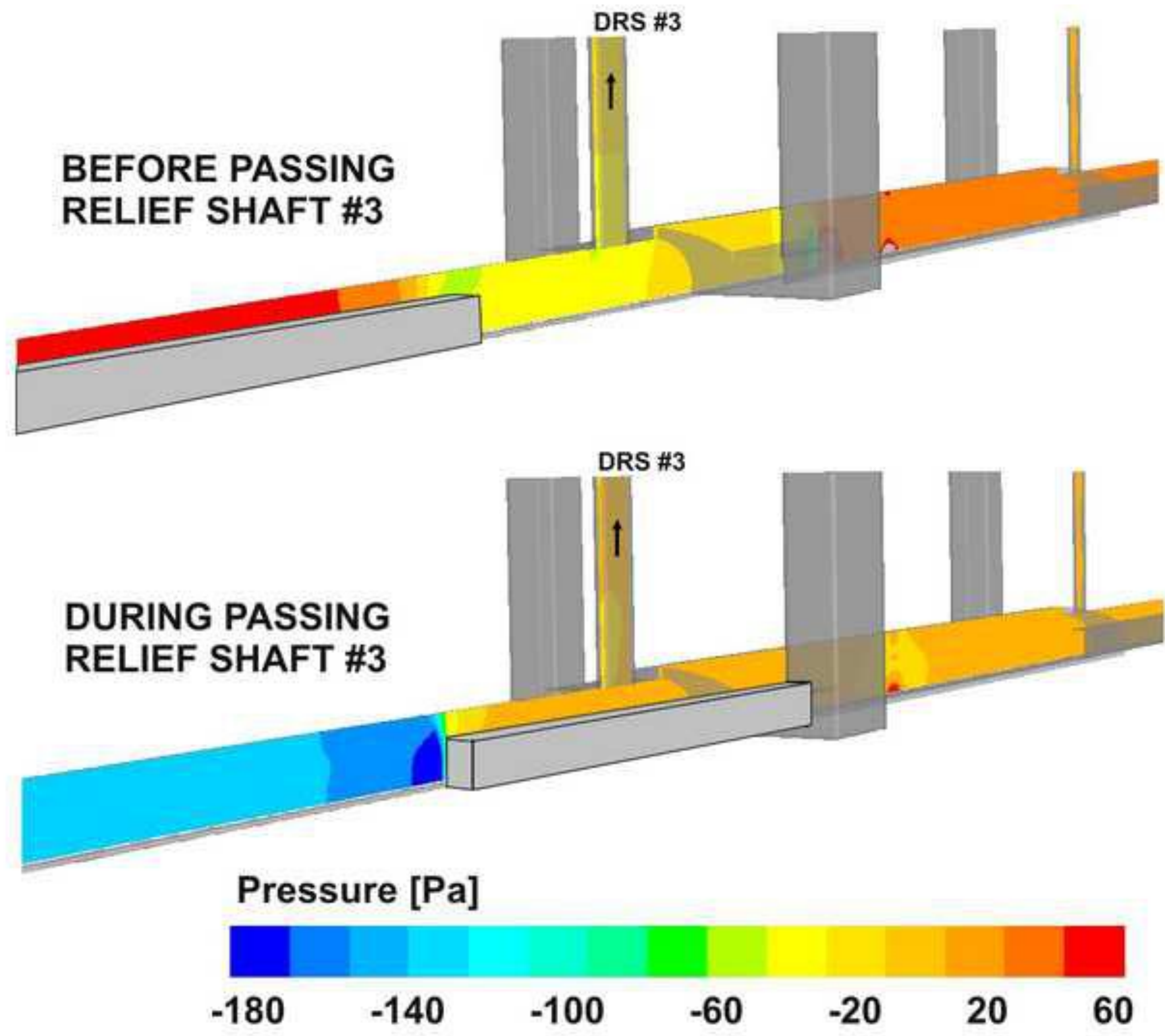


\section{Figure 11}

Click here to download high resolution image

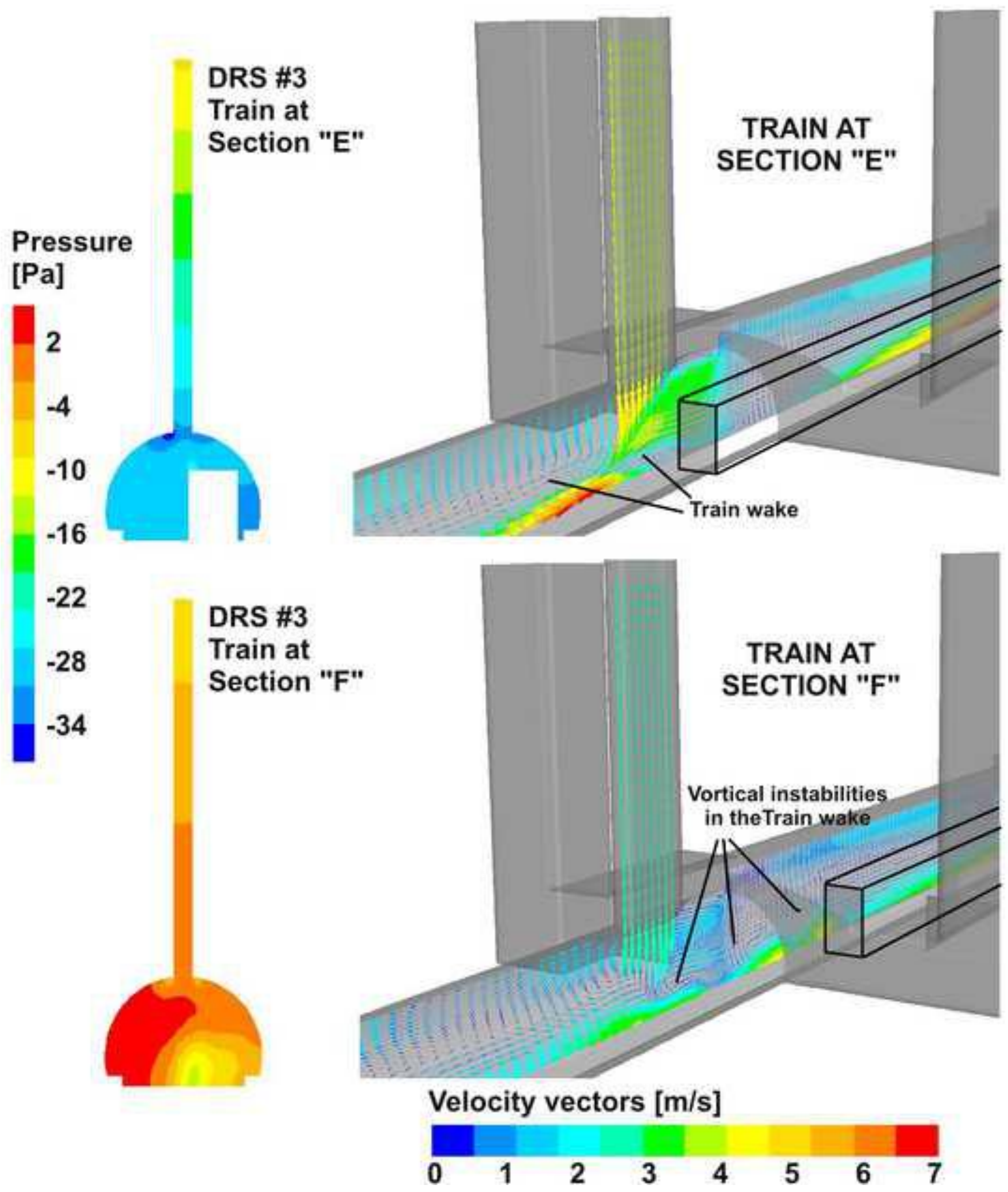



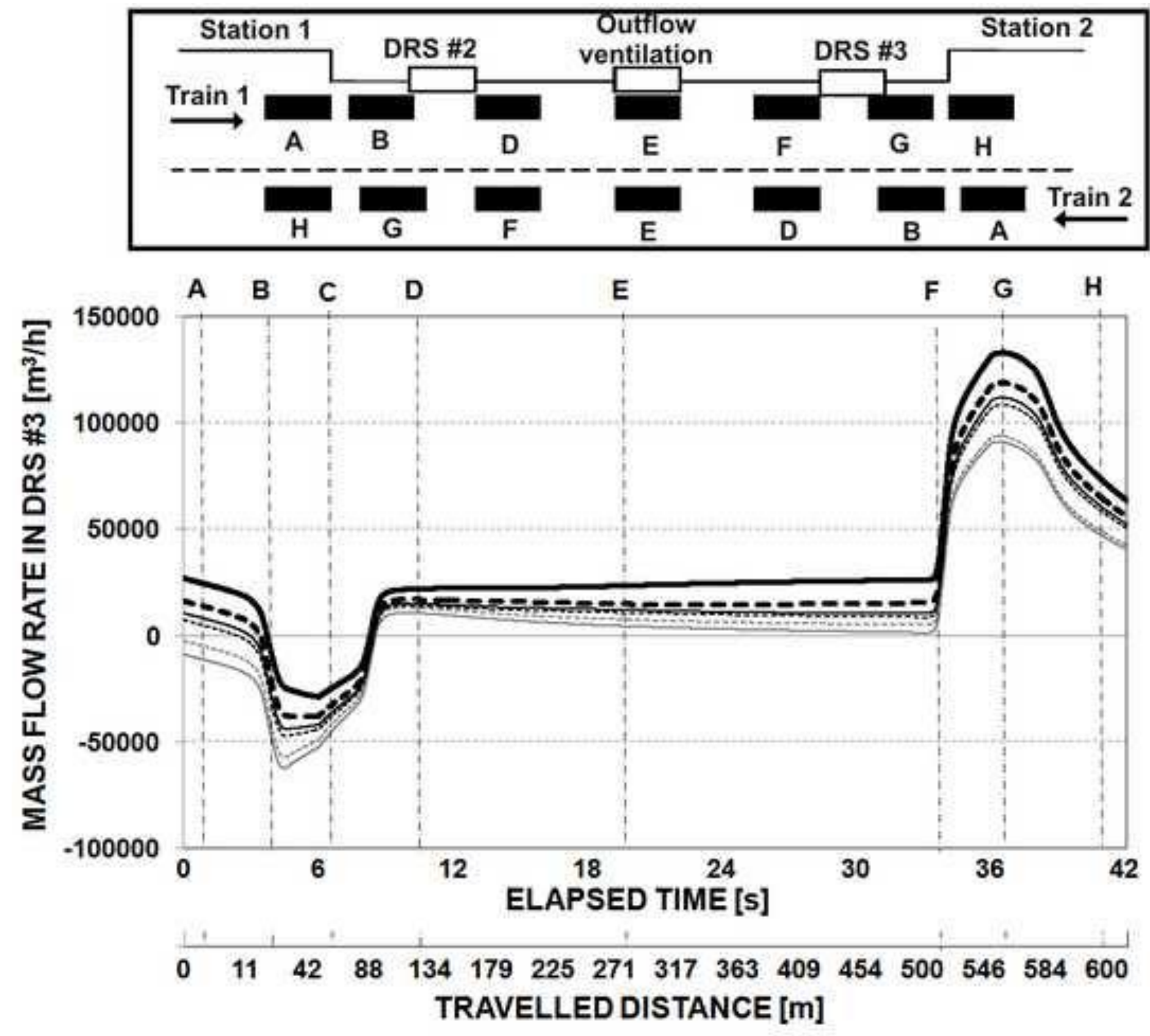

\begin{tabular}{|ll|}
\hline$\ldots$ Natural ventilation & - w/o Mechanical extraction \\
$\ldots . .$. Infra-ventilation & - Under-ventilation \\
- Neutral ventilation & - Over-ventilation \\
\hline
\end{tabular}



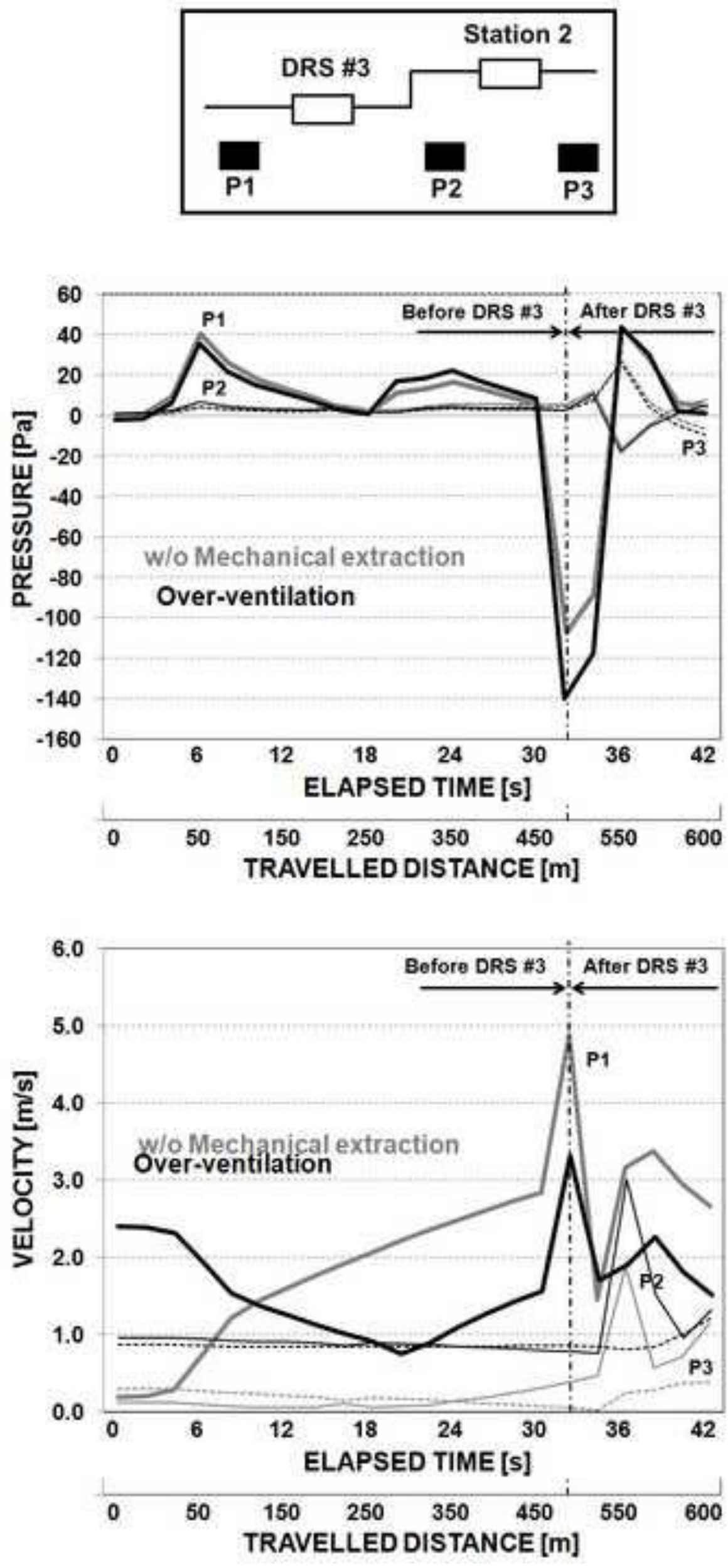

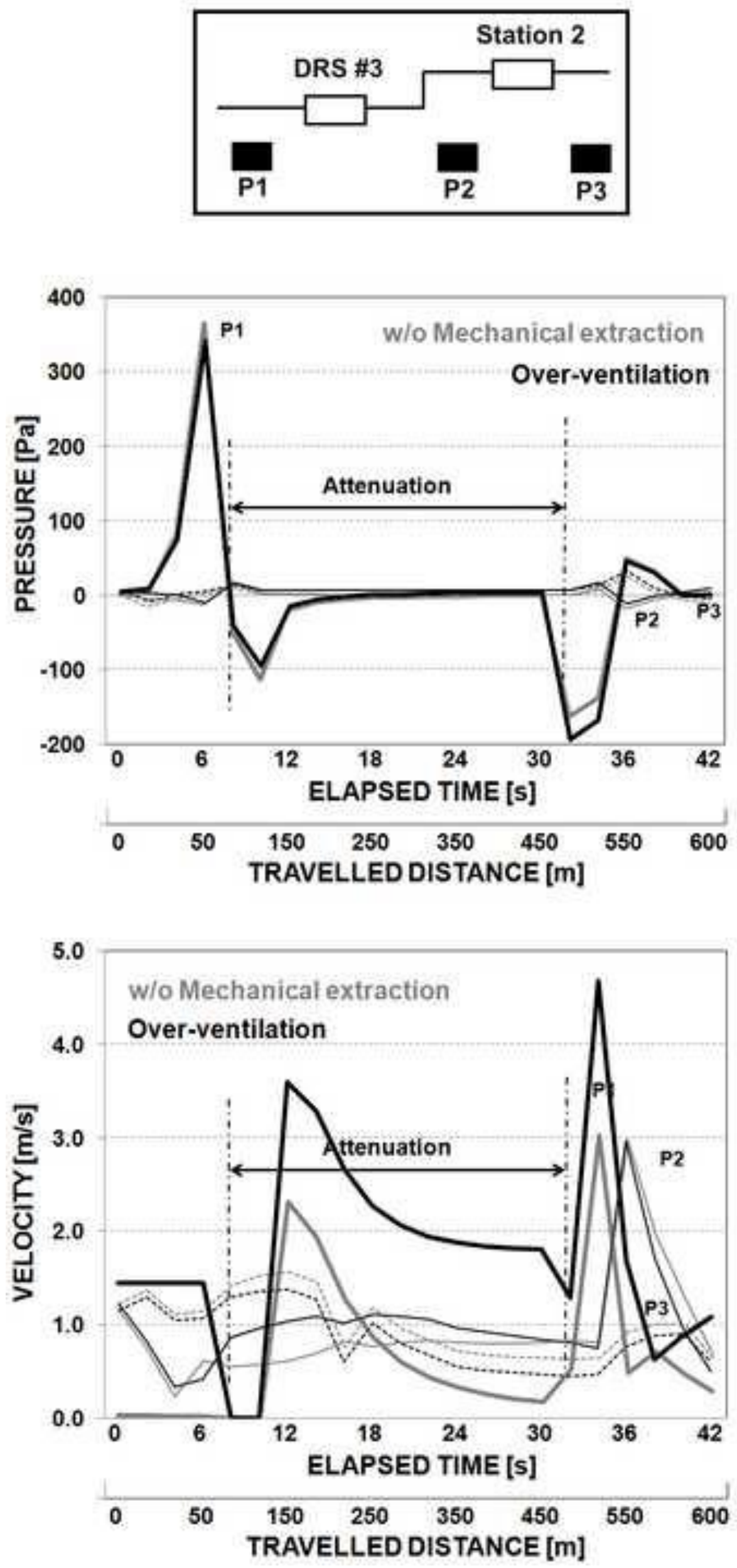

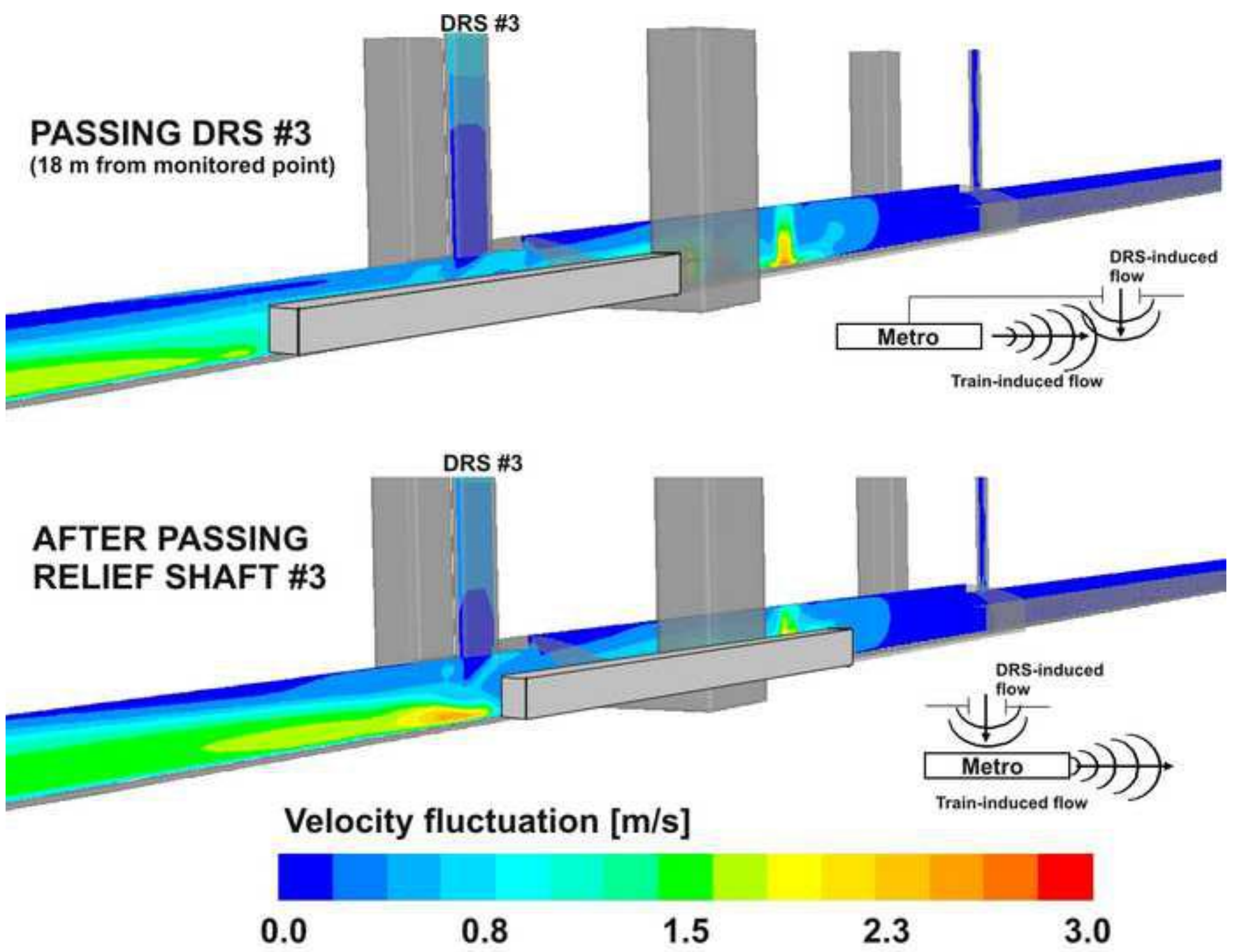
Figure 16

Click here to download high resolution image

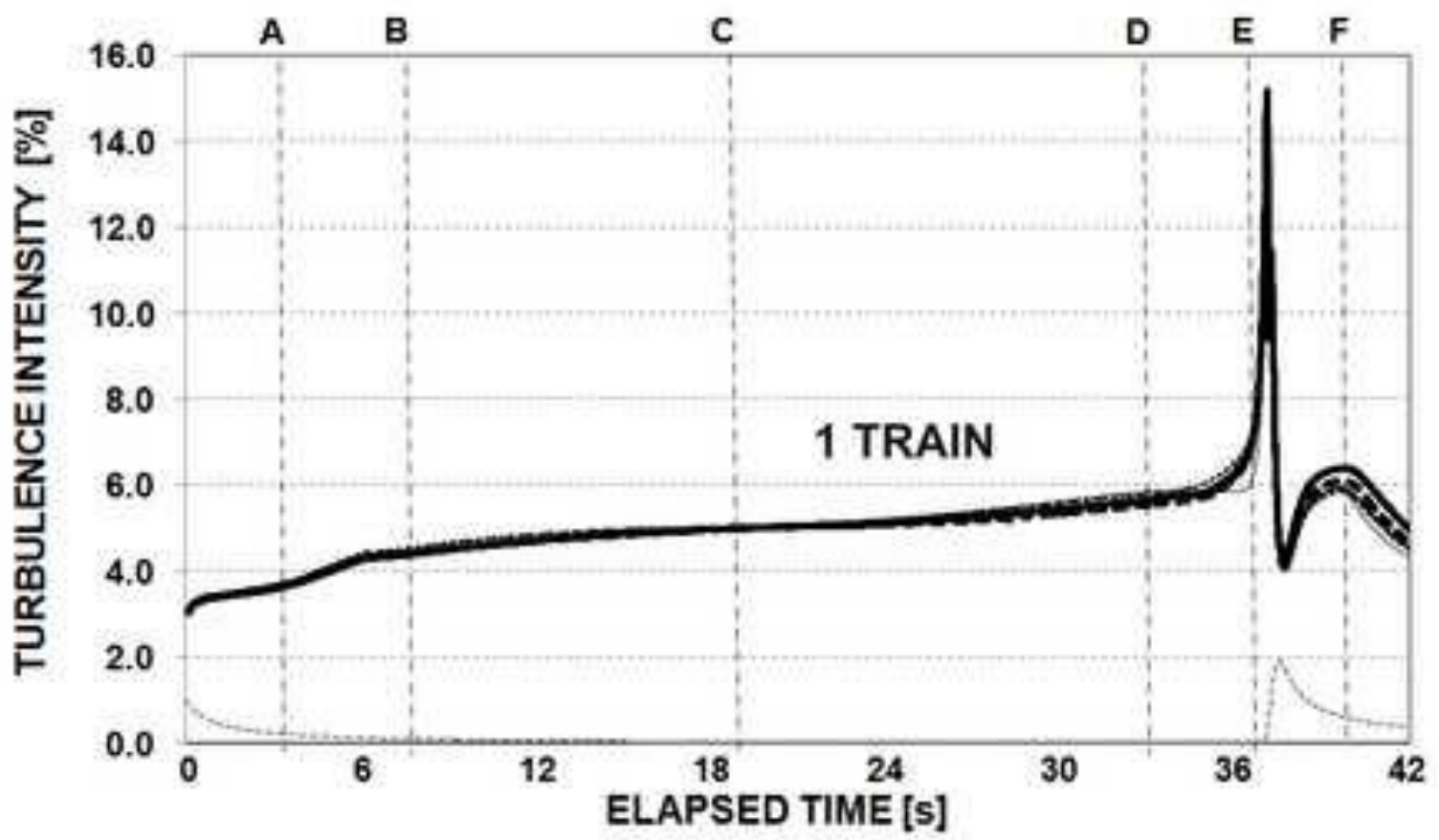

$\begin{array}{llllllllllllllll}0 & 11 & 42 & 88 & 134 & 179 & 225 & 271 & 317 & 363 & 409 & 454 & 500 & 546 & 584 & 600\end{array}$ TRAVELLED DISTANCE [m]

\begin{tabular}{|ll|} 
Natural ventilation & - W/o Mechanical extraction \\
- Infra-ventilation & - Under-ventilation \\
- Neutral ventilation & Over-ventilation \\
\hline
\end{tabular}

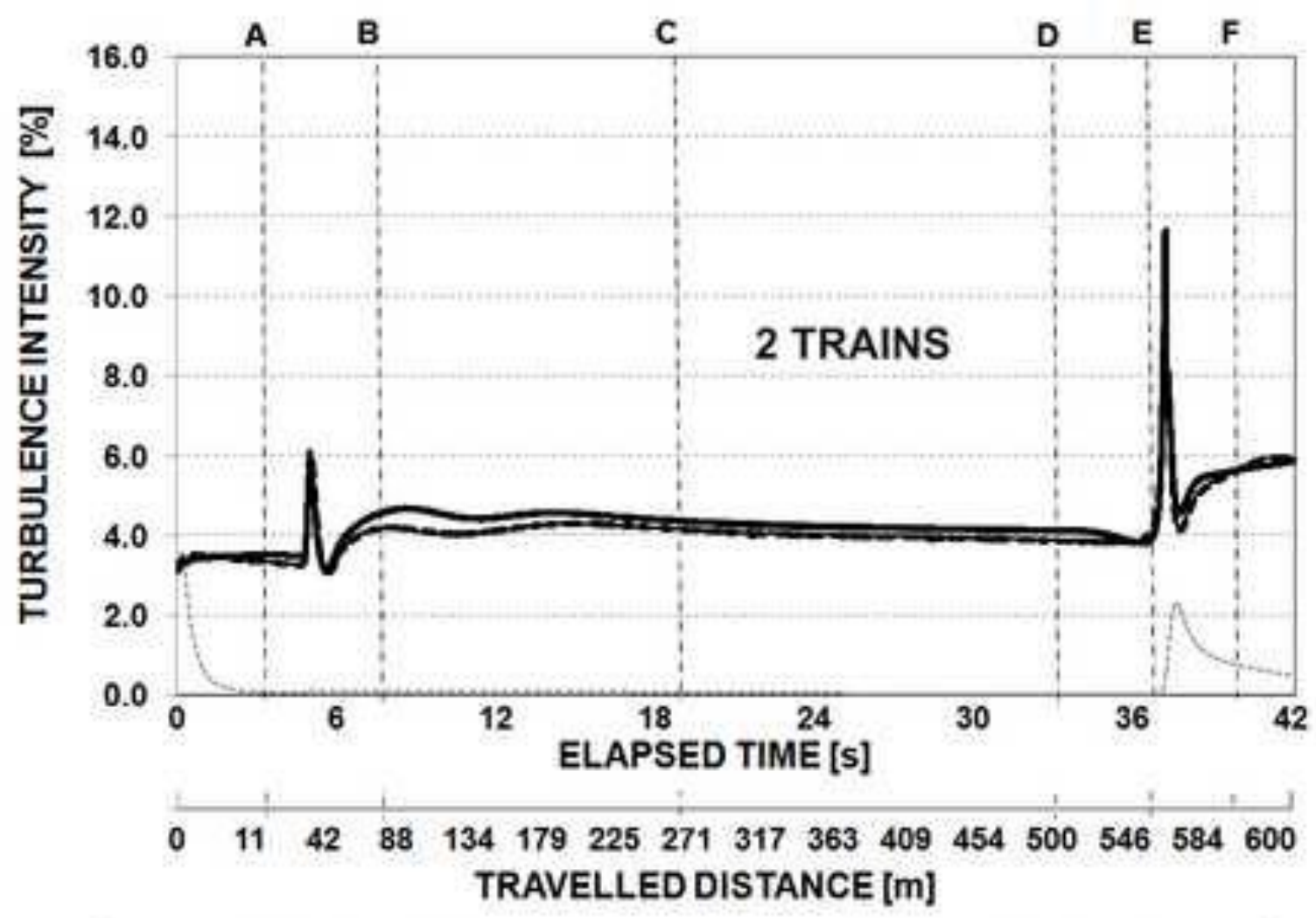


This document is a pre-print version of the scientific paper published by Elsevier. It has been released by the authors to fulfill all the publisher requirements established for Article Sharing: https://www.elsevier.com/about/policies/sharing

\section{(9) $\Theta \Theta \Theta$}

(C) 2019. This manuscript version is made available under the Creative Commons Attribution-NonCommercial-NoDerivatives 4.0 International License (CC-BY-NC-ND 4.0 license) http://creativecommons.org/licenses/by-nc-nd/4.0/ 